\title{
N 0
}

de arquitectura

Foro: Proceso de titulación de arquitectos en la Universidad de Chile

Forum: Graduation process

of architects, Universidad de Chile

El lugar: Confitería Torres / La fecha: 22 de julio de 2005 / El tema: El proceso de titulación.

Los participantes:

Place: Confitería Torres / Date: July 222005 / Topic: Graduation process.

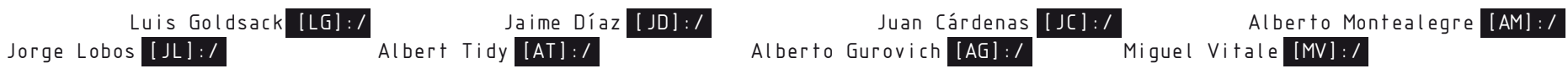

Fotografías por: Cecilia Wolff [CW] / Pablo Cid [PC] / Diego Vallejos [DV] / Samuel Linker [SL]

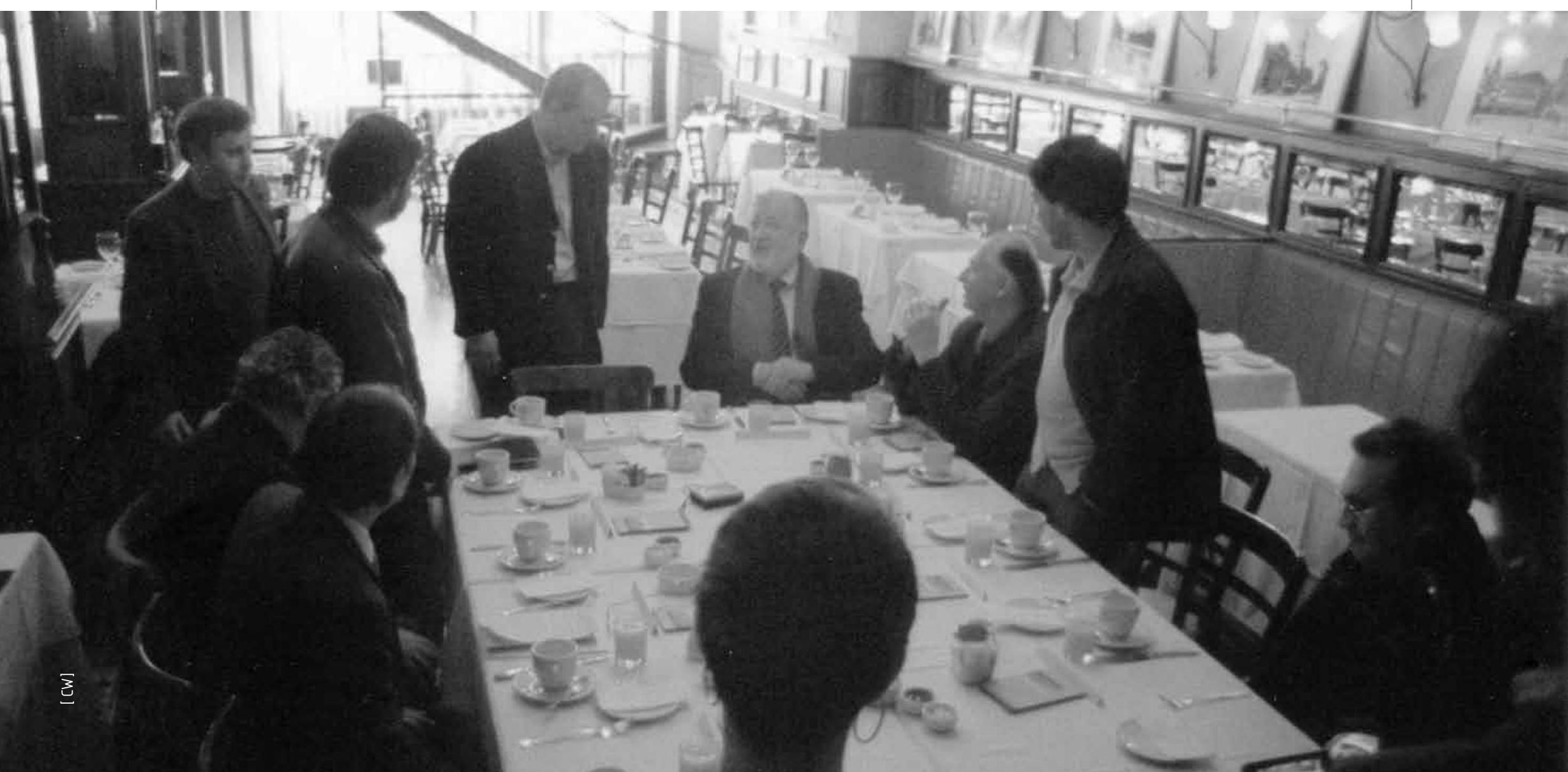



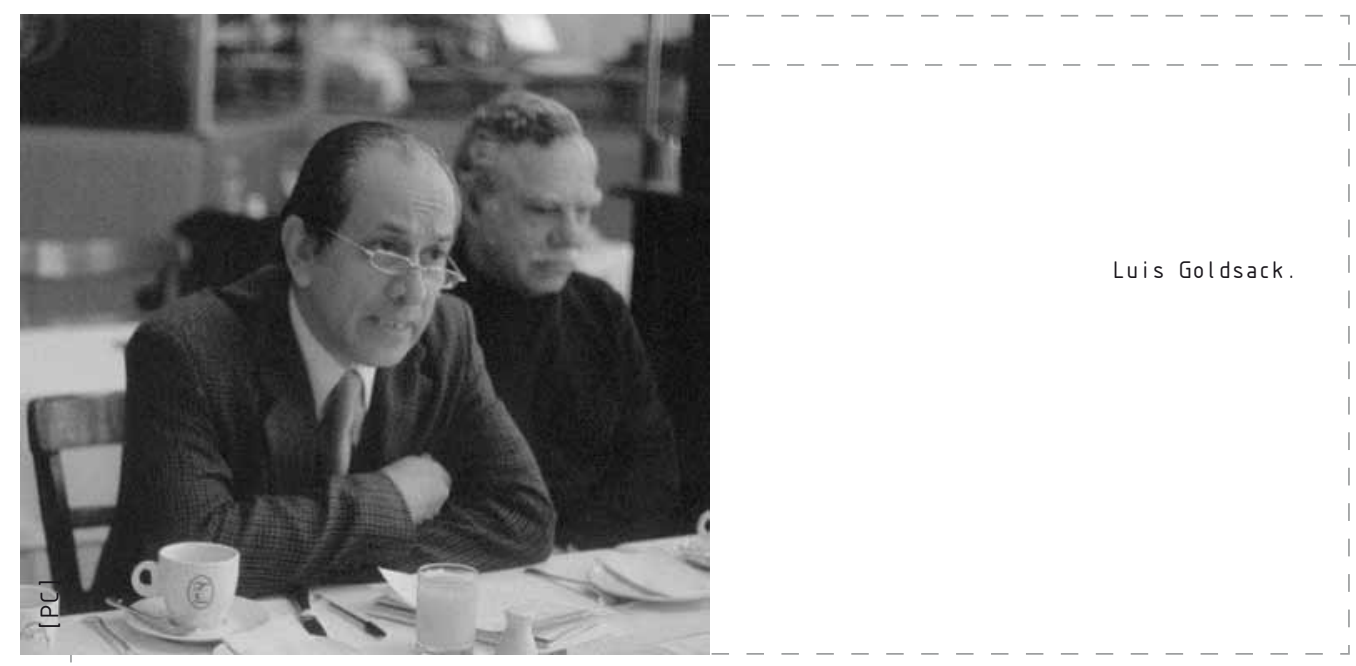

\section{(LG) : /}

A nombre de la Revista De Arquitectura me corresponde darles la bienvenida a este estupendo lugar, la Confitería Torres, un edificio notable por su valor patrimonial, gracias a la gentileza de su dueño don Claudio Soto quien nos recibió hoy... Quisiera agradecer especialmente la presencia de cada uno de los profesores que nos acompañan: el profesor Juan Cárdenas, el profesor Alberto Montealegre, el profesor Jorge Lobos, el profesor Alberto Gurovich, el profesor Albert Tidy, el profesor Jaime Díaz, y el profesor Miguel Vitale, a todos ustedes nuestro reconocimiento...

Quisiera partir con unas palabras, que extraje de la revista de arquitectura número uno, dice:

"Sentimos la Revista De Arquitectura como una responsabilidad ineludible desde nuestra condición de Universidad de Chile, ya que esperamos que ella transmita el producto de un pensamiento reflexivo y sereno, decantado en el tiempo, sin que tenga en ella cabida la superficialidad apresurada o la palabra vacía. Deseamos que refleje el carácter pluralista de nuestra universidad y que por lo tanto la discusión teórica fundada esté presente y sea siempre fecunda. Llamamos a todos aquellos que forman parte de nuestra comunidad a participar activamente en la producción de esta revista, para que crezca y se desarrollo libremente como algo propio, creativo y permanentemente apasionante...".

Con estas palabras el ex decano de nuestra Facultad, Mario Recordón, refundaba la revista de arquitectura en noviembre del año 90. En este sentido es que al retomar este proyecto, el equipo de trabajo, el comité editorial de la revista dirigido por el profesor Constantino Mawromatis, creyó interesante iniciar formalmente sus actividades con un foro en relación a un tema que nos interesa tanto a los académicos como a los alumnos de la Facultad, y que trasciende a nuestra facultad: el proceso de titulación de la carrera de arquitectura...

Siempre nuestra revista consideró interesante mostrar proyectos de título destacados como una manifestación concreta de nuestro quehacer docente, en un marco de reflexión sobre los objetivos, alcances, contenidos de esta etapa, en vista de los profesores que han participado largamente en ella; pretendemos abrir espacios de discusión e interacción que permitan a la Facultad de Arquitectura y Urbanismo contextualizarse en los nuevos escenarios profesionales y académicos, tanto a nivel local como global.

Para orientar el debate se planteó un temario base de referencia que considera cinco grandes temas que tienen relación con el proceso de titulación.

Quisiera ofrecer la palabra en primera instancia al profesor Jaime Díaz.

\section{$(J D): /$}

Es por todos conocido que en las últimas décadas han ocurrido cambios tanto en el medio profesional de los arquitectos como en las instancias formativas. Vivimos los cambios recientes que han multiplicado el número de universidades y por ende el número de estudiantes, y no sólo el número sino las condiciones: estamos pasando de universidades gratuitas a universidades pagadas, hemos sufrido la fuerte disminución de los aportes estatales a la educación superior. Todas son circunstancias que afectan a la educación superior, y en el ámbito profesional también han ocurrido cambios que han afectado el desempeño de los arquitectos. Ya algunos estudios realizados a comienzo de la década de los noventa nos adevertían que los arquitectos no sólo se dedicaban al tradicional oficio de proyectar sino que habían diversificado su campo buscando nuevos derroteros profesionales. En nuestra Facultad esa discusión comenzó, yo diría, a comienzos de los noventa con el decanato del profesor Haramoto. Pero durante mucho tiempo no pudimos efectuar los cambios, sino hasta que fueron refrendados por varias evaluaciones externas. La Escuela de Arquitectura como ustedes saben, fue evaluada primero por un equipo dirigido por Ángela Schweitzer, luego por una comisión de la asociación acreditadora norteamericana NAAB y posteriormente por el Royal Institute of British Architects (RIBA), entidad que acredita actualmente. Todas esas evaluaciones coincidían en que nuestro currículum era excesivamente rígido para una profesión que tenía un campo muy amplio... y eso es lo que intenta recoger el plan del 98 : diversificar en la medida de lo que los propios académicos estábamos dispuestos a aceptar y preparar mejor a nuestros estudiantes para la vida profesional... De esa forma se gesta el currículum actual, el cual tiene un porcentaje bastante alto, aproximadamente un cincuenta por ciento de asignaturas electivas en que los estudiantes pueden elegir dentro de las áreas que la facultad desarrolla; y se garantiza el otro cincuenta por ciento con las llamadas asignaturas fundamentales. Además este plan intentaba permitir la mayor velocidad de generación de conocimiento actual, los planes en general, no sólo en arquitectura, en cualquier carrera universitaria, no dura más de una generación; seis, siete años y ya nuevamente tiene que ser revisado, porque la velocidad y el avance del conocimiento es mucho mayor que hace algunas décadas. Entonces el plan contempla ciertos espacios para que se vayan regenerando y renovando algunas líneas de conocimiento en forma constante. Lo que yo diría que no ha cambiado en su formación y que quizás da la continuidad en nuestra centenaria historia, es que el proyecto sigue siendo el método fundamental de la formación y es aquello que caracteriza a la formación de arquitectura; hoy en día el método de proyecto es acogido incluso por otras disciplinas, y están interesadas en adoptarlo como un método educativo en general, formar a través del proyecto; a veces nosotros no somos conscientes de la 

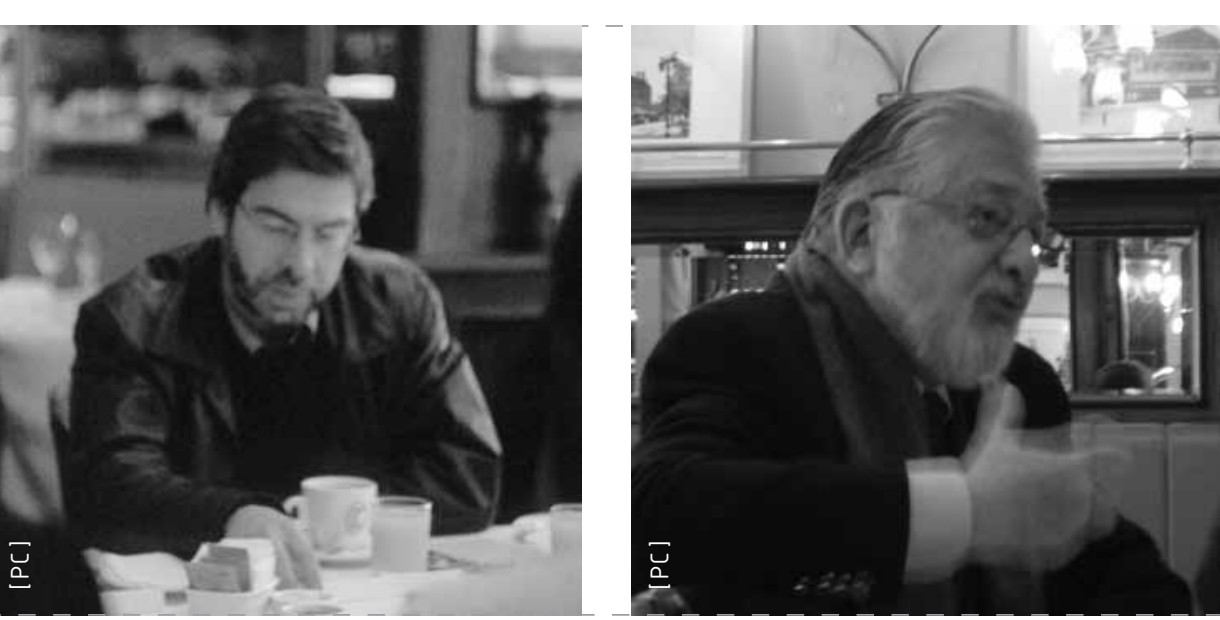

importancia de esta metodología, no sólo el taller como instancia colectiva de educación sino el proyecto como método de aprendizaje y eso sigue siendo hoy en día una de nuestras principales fortalezas. Entonces por un lado tenemos un método bastante eficaz y por otro lado tenemos que adaptar ese método a las circunstancias del sistema de educación superior actual... Yo creo que en ese marco deberíamos situarnos.

\section{(LG) : /}

Gracias Jaime... le ofrecí la palabra precisamente a usted para que nos diera el marco de referencia en que hoy día se encuentra el proyecto de título.

\section{$(\mathrm{JC}): /$}

Creo que la revisión de los objetivos del plan de estudios es una cuestión impostergable; efectivamente, los cambios ocurridos en todo lo que significa el campo laboral del arquitecto, ha ido a una velocidad bastante mayor que la que la facultad ofrece. De hecho que haya un cincuenta por ciento de currículum flexible y cincuenta por ciento de currículum base, no garantiza, per se, que haya esta suerte de adaptabilidad en la formación; nuestra formación sigue marcada fuertemente por el perfil del arquitecto diseñador, un hombre que va a enfrentar el campo laboral mediante el ejercicio de una profesión marcada por los proyectos de arquitectura. La revisión de los planes de estudio es impostergable porque es necesario reacondicionarlos. Es importante poder echar una mirada hacia atrás y ver cómo estos objetivos que se habían planteado se cumplieron o no en el Plan de Estudios vigente.

El segundo punto que nos convoca, habla de la titulación FAU, dice, "proyecto o tesis de título u otras alternativas". Pienso que el proyecto de título no debe confundirse, no debe asimilarse a que sea "la" prueba habilitante para el ejercicio profesional; creo que el sistema debe ir paso a paso habilitando a los alumnos para el ejercicio profesional, en cada etapa éstos deben ser evaluados para ser posteriormente habilitados para el ejercicio profesional; pienso que la etapa que termina en la calidad de egresado, en quinto año, es la culminación de un proceso formativo en esa perspectiva. En ese contexto el sexto año debiera transformarse en una cuestión diferente, ni académica cien por ciento, ni profesionalizante; debe ser la oportunidad en que el alumno efectivamente, ya capacitado, pueda explorar otras formas, hacer nuevas proposiciones, o sea el proyecto o la tesis o lo que fuera que constituya esa instancia, debe ser propositiva...

Para lograr eso se debe tender a que no se exponga al alumno en ese nivel a otra validación de sus capacidades para el ejercicio profesional; eso, creo que debería ser visado por la escuela, a nivel de quinto año..

Sí es importante ver cómo con esta formación es posible hacer propuestas innovadoras y personales que naturalmente tienen que tener una sustentación firme en todo lo que constituye el acervo cultural, y el desarrollo de las capacidades y habilidades del alumno... Por eso hago hincapié en que la titulación no es ni la experiencia académica final ni es la primera experiencia profesional.

Otro punto que me interesa recalcar es el siguiente: en nuestra formación a través de los cinco primeros años en nuestra escuela, es la línea de taller el eje central que conduce toda la parte formativa; en ese tiempo existe una suerte de tutelaje de parte del profesor con respecto al proceso formativo de los alumnos; éstos ven a su profesor con una imagen importante y no es raro observar en los talleres que se hace arquitectura "a la manera de..."; son pocos los alumnos inquietos que hacen una trayectoria vertical y horizontal que les permita tomar varias visiones, yo diría que es difícil poder separar lo que es propio del alumno, de lo que es un elemento asumido de parte de la visión particular que el profesor pueda tener, en cambio, pienso, el sexto año debe buscar que el alumno se exprese con absoluta libertad... El profesor pasa a ser un referente cuestionador, que lo ayude, que lo incite, que lo provoque, pero de ninguna manera que lo marque. Por eso asumo, que el alumno, en su paso por cinco años, ya debe tener definida su propia personalidad, decantada su particular forma de aproximarse a la arquitectura.

\section{(AM) : /}

Creo que el proyecto de título es un aspecto que debe analizarse en el contexto del Plan de Estudios. En ese sentido yo partiría poniendo aquí en la mesa una cosa que todos sabemos, pero que me sirve como introducción a la forma en que yo pienso que debería abordarse este tema. He sabido que las postulaciones a las escuelas de arquitectura en este último año han disminuido. Hace quince años, Arquitectura era la carrera de mayor prestigio y junto con Medicina o Ingeniería, concentraba los mayores puntajes. Me comentaban el otro día, no recuerdo exactamente las cifras estadísticas, que una Universidad en Santiago, que tenía cupo para ciento cincuenta postulantes habría llenado solamente el cincuenta por ciento de los cupos, que lo mismo habría sucedido con su sede en Concepción. Otra persona me contaba, no me consta, a lo mejor alguno de ustedes podría confirmarlo, que otra Universidad, sencillamente había tenido que salir a llamar por teléfono a los candidatos y ya no había, sencillamente, como llenar el total de los cupos. ¿Qué significa esto?

Significa que se ha tomado conciencia de que la carrera de arquitectura no es esa cuestión brillante que sospechaban algunos, sino que sencillamente en el campo de la arquitectura hay muy poco espacio para el trabajo. De hecho los muchachos se han 


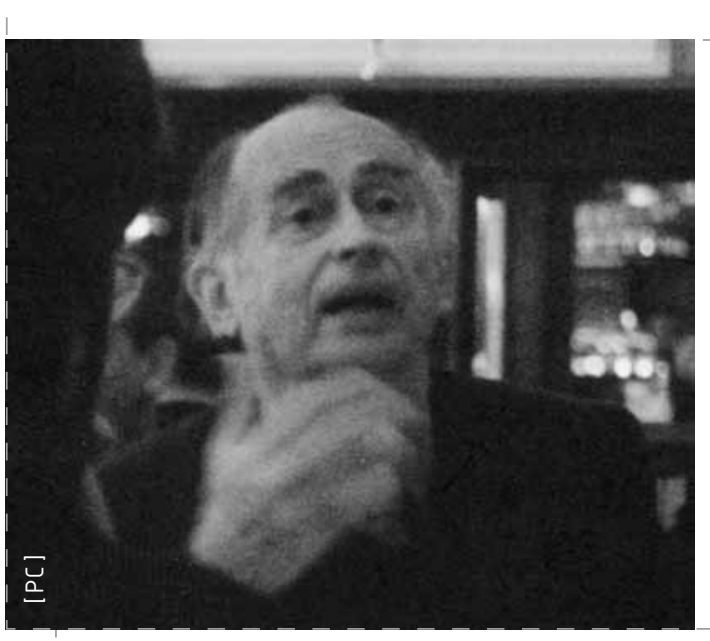

dado cuenta de eso y han dejado de postular a Arquitectura. La cantidad de currículum de postulantes que me llegan a la oficina mensualmente es por lo menos de unos cinco, de gente que quiere trabajar, que anda buscando trabajo.

¿Cuál es a mi juicio el fondo del problema y qué tiene que ver con el proyecto de título? El proyecto de título tiene que ver con la imagen que tenemos nosotros, con el paradigma que hemos construido acerca de lo que tiene que ser el arquitecto. En éste, el arquitecto queda definido exclusivamente en su aspecto creativo.

La especificidad profesional que pueda tener la carrera de Arquitectura es una cuestión que no tiene hoy ninguna acentuación. ¿Esto por qué? Porque nuestro paradigma está basado en el ambiente de las revistas de arquitectura, en el star system. En el estrellato de la arquitectura. El valor específicamente profesional de la arquitectura se desprecia. De hecho, la única manera de titularse en la escuela era el Proyecto de Título. Recientemente entiendo que se ha abierto, y me parece una cosa muy positiva, la posibilidad de titularse con una Tesis. Sin embargo resulta que esa tesis no está apoyada por una organización, por un esquema en el Plan de Estudios, que conduzca verdaderamente a una especialización.

Hoy día el campo profesional está dominado fundamentalmente por la ingeniería: los grandes proyectos, o muchos de ellos que se están desarrollando, son encargados a oficinas de ingeniería porque el arquitecto es considerado casi innecesario. Si no es un arquitecto de mucho prestigio, la arquitectura se transforma en una cuestión secundaria y el proyecto de arquitectura es más bien una herramienta de transacción dentro de un equipo profesional en que aparecen distintos requisitos de cada una de las especialidades.

La misión de la Universidad es fundamentalmente producir, entregar los profesionales eficientes que el país necesita.
Por ahí parte la cosa, por crear una plataforma básica. Sobre la cual, emergerán las personas de talento que de todas maneras van a sobresalir.

Entonces creo que lo primero que hay que hacer es establecer un Plan de Estudios que, quizás, en los cuatro primeros años sea una cosa muy parecida a la que nosotros tenemos hoy día, pero que en sus dos últimos años sea verdaderamente un lugar en que los alumnos puedan encontrar distintas ramas, distintas líneas, podríamos decir, de especialización. Desde luego una línea de especialización que está muy madura en la escuela y que es una realidad, es la línea de urbanismo. Otra línea de especialización que está muy consolidada es todo lo que tiene que ver con gestión inmobiliaria, con administración de obras.

Me he encontrado en una municipalidad con un ex alumno que está al otro lado del escritorio para atender una consulta. Está acomplejado porque yo lo estoy viendo en una función que él estima poco menos que indecorosa. Él está sentado detrás de un escritorio y el arquitecto que le metieron en la cabeza lo único que podía hacer eran edificios. Resulta que en su función puede ser una persona absolutamente creativa y positiva para la sociedad. El gran problema es que cuando él está al otro lado del escritorio es un autodidacta, porque sencillamente lo que le enseñaron en la Universidad no le sirve para lo que él está haciendo allí.

Otro ejemplo: me encuentro con un alumno que llega a una municipalidad, lo saludo, tiene una magnifica camioneta, sensacional, parece un gran barco petrolero. Lo felicito. Conversamos y acomplejadamente me dice que está dedicado a la construcción. Le pregunto ¿cómo haces tus estudios de presupuestos? ¿Manejas una planilla de cálculo? No, me dice él, sigo usando la calculadora.

Esa es la realidad de lo que estamos formando, unos arquitectos abstractos, una carrera de arquitectura que se está desvalorizando, que tiene cada vez menos impacto en la sociedad y en los equipos profesionales. Entonces creo que el Proyecto de Título tiene que ser sólo una de las instancias de titulación.

Así como creo que en los dos últimos años tiene que haber una especialización en urbanismo, construcción, etcétera, tiene que haber especialización en diseño para algunos alumnos, no para todos. No todo el mundo tiene la facilidad de ser buen diseñador. Entonces en ese grupo juntemos a los mejores diseñadores que le den prestigio, que le den brillo público, qué sé yo, a la escuela. Al resto démosles una formación profesional que sea útil y yo creo que el Plan de Estudios en ese sentido hay que reformarlo. Hay que hacer ajustes al Proyecto de Título mismo, pero, honradamente, me parece que son una cuestión casi cosmética, en relación con lo que hay que hacer en cuanto a reformulación del Plan de Estudio.

Esto lo encuentro difícil, no imposible. Crear los cuerpos docentes que sean capaces de adaptarse a estas nuevas relaciones en el campo laboral no es nada fácil. Pero creo que hay que comenzar a hacerlo ahora, o si no estamos contribuyendo a crear una realidad inverosímil.

Entonces, resumiendo, creo que el Proyecto de Título tiene que ser, sencillamente, una instancia más. Deben haber otras maneras de recibirse como arquitecto. Al final todos serán arquitectos, todos tendrán derecho a ejercer. Si quieren proyectarán casas, si quieren se dedicarán a los negocios inmobiliarios, podrán trabajar en una municipalidad, podrán proyectar. Todos tienen el mismo título de arquitecto, pero a cada uno yo le daría, por ejemplo, además de él algo así como un minor, un diploma anexo, que certifique que los alumnos que salen de nuestra escuela tienen una especialización y competencia singular en un determinado campo. 


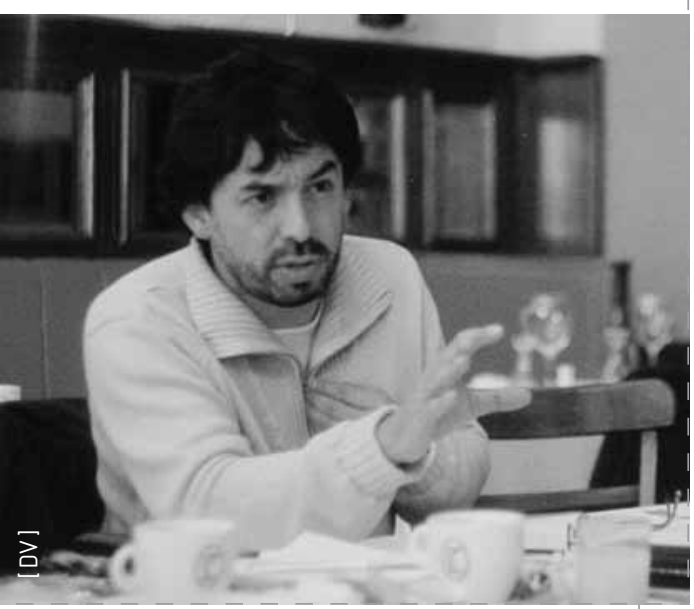

\section{$(J L): /$}

Mi opinión es bastante coincidente con las anteriores.

Primero, partiendo por lo que decía Alberto, sobre el paradigma del proyecto de título como expresión última de la carrera. Efectivamente eso impacta el plan de estudios. Como también impacta si la Universidad de Chile, fuera nuevamente gratuita o con arancel diferenciado. Sería otro plan de estudios, reformulación que debiese hacerse a partir de cuál es la misión de la universidad pública, que es el tema que Jaime tocó al inicio -muy distinto al de una universidad pagada, que restringe el espectro de estudios al margen de lo financiable-. Una universidad gratuita y pública, donde puedan acceder efectivamente las personas que tienen capacidad de las clases sociales menos favorecidas, tiene otro plan de estudios, y por consiguiente otra forma de titulación, quizás donde se privilegien los temas sociales o de utilidad pública de la arquitectura, o también donde la forma de titularse pueda ser trabajando en algún municipio o institución pública, no sólo como modo de retribución al país por su formación.

Lo segundo, respecto a la misma pregunta, es un estudio realizado en el curso de posgrado sobre asentamientos humanos de la Universidad Politécnica de Madrid, que dirige un ingeniero de caminos español, no un arquitecto. Este estudio habla acerca de la especialización de los arquitectos, a qué se dedican realmente los arquitectos en el planeta, cuestión interesantísima para la formación profesional... dice: del cien por ciento de los arquitectos que se titulan y trabajan de arquitectos, el $90 \%$ de ellos trabaja para el diez por ciento más rico de la población; segundo dato: dos tercios de la población del mundo, es decir 4.000 millones de seres humanos, no tiene acceso a ningún producto de la arquitectura, ni material de construcción prefabricado, ni ingeniero, ni constructor... o sea los arquitectos se dedican solamente a dos mil millones de seres humanos, para los otros cuatro mil millones no hay ningún arquitecto que tenga ninguna incidencia en sus vidas... De esos dos mil millones, los arquitectos sólo se dedican al diez por ciento más rico, doscientos millones... ahora, qué arquitectos son los que efectivamente diseñan: no más allá del ocho o nueve por ciento son los que se dedican al diseño y de ese porcentaje... o sea ya estamos en que del cien por ciento de los arquitectos que trabajan en arquitectura, solamente el diez por ciento se dedica al diseño, y de ese diez por ciento solamente un décimo se dedica al diseño por encargo, los otros diseñan para inmobiliarias, para proyectos anónimos, para proyectos masivos, para proyectos urbanos, para proyectos públicos... para una dinámica distinta al proyecto por encargo que paradojalmente es lo que sustenta la formación en nuestras escuelas: el profesor de taller encarga un proyecto, para que los estudiantes respondan a ese encargo, es decir, estamos educando para el uno por ciento del trabajo que realmente hacen los arquitectos... o dicho de otro modo estamos educando en taller, sólo para el $10 \%$ de los arquitectos que realmente trabajan en diseño.

Este dato me parece relevante, en relación a cuál es la distorsión que se produce en la enseñanza de la arquitectura. Las escuelas de arquitectura que formulan todo su plan de estudios, toda la energía, todos los profesores, todos los años que hay detrás de eso, para formar solamente la función que va a cumplir un porcentaje de los alumnos. Esto quiere decir que hay un desfase gigantesco...

El tercer punto, tiene que ver con los nuevos roles de los arquitectos, y viejos roles no asumidos, como los que mencionaba Alberto; los arquitectos que trabajan en la administración pública, los arquitectos gestores, los arquitectos constructores, entre una serie de trabajos para los que no está formando la escuela; y en los nuevos roles, como el de activista cultural. Un ejemplo, una arquitecta de la Universidad de Chile se va a un pequeño pueblo en el sur, Dalcahue. Ese sólo hecho ya es una dinámica de cambio para esa población, independientemente del proyecto que ella haga. El objetivo de la escuela sería en este caso, la arquitecta. Ella es el proyecto, porque en el momento en que se instala en una comunidad pequeña genera una serie de dinámicas y transformaciones... es decir da lo mismo lo que ella haga o diseñe, el tema es como ella se transforma en una activista cultural y ese es un nuevo rol, que quizás no tenemos del todo asumido... Lo mismo ocurre para ciudades como Santiago, no sólo en las pequeñas comunidades.

\section{(AT) : /}

Bueno, cuando se habla de cambios en el plan de estudios... Primero diría que nuestra escuela de arquitectura no es cualquier escuela, es la más grande, antigua, la más diversa y, a pesar de lo que dice Jorge, dentro del contexto nacional, también la más pública. Entonces yo creo que cuando se habla de cambios hay que entenderlo dentro de una tradición de ciento cincuenta y seis años, que no ha sido absolutamente equívoca. Al menos, considero haber recibido una muy buena formación en ella... creo que los alumnos que siguen instancias de perfeccionamiento, estudios de posgrado, brillan por sus condiciones, a diferencia de otras instituciones que tal vez no ponen un acento en una formación compleja... la formación que recib yo tal vez es un poco distinta de la que se recibe actualmente, pero es una característica del arquitecto egresado de esta escuela, que es un profesional altamente capacitado. Dentro de la oferta del mercado, los arquitectos de la Universidad de Chile, tienen una marcada preferencia dentro del campo ocupacional disponible, a diferencia de otras instituciones. Eso hay que valorarlo.

Ahora la discusión de si nuestra formación debería ser cargada hacia el espectro politécnico o hacia el lado de la formación Beaux Art, es una larga discusión. El tema de la diversificación versus la especialización 


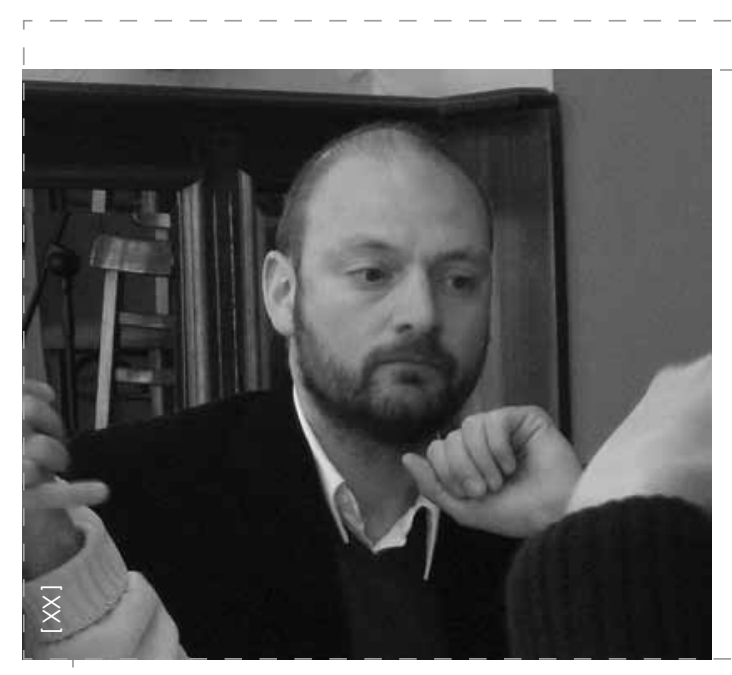

también lo es. No creo que sea un problema de oferta laboral ni de necesidad, no son cosas equivalentes, porque si la necesidad de arquitectos estuviera cubierta viviríamos en una ciudad fantástica y creo que el problema que existe es el nexo entre el potencial disponible de arquitectos y los campos ocupacionales. En ese sentido coincido en que el arquitecto, probablemente, es un profesional de baja credibilidad, y tal vez por eso no ocupa los lugares que debería ocupar en las posiciones de poder.

Ahora creo que hablar de arquitecto diseñador no equivale, necesariamente, a un concepto peyorativo, creo que un arquitecto puede no dedicarse al campo del diseño, pero también es importante que cumpla con una formación completa y creo que el perfil del arquitecto de la Universidad de Chile tiene que ver con eso, tiene que ver con un profesional altamente capacitado y altamente formado...

Hoy día el plan de estudios contempla posibilidades de titulación distintas a las que existían antes, son más flexibles, hoy, con la eliminación, supresión o reemplazo del taller profesional, por la práctica profesional, se tiene que en algunas instancias constituye un valor positivo dentro de la formación del alumno, pero los profesores de título han notado de alguna manera la ausencia del quinto año... era un año que cumplía con definir el perfil de los arquitectos... el alumno que hace quinto año, vía práctica profesional, termina su formación como arquitecto en cuarto año y pasa un año y medio desvinculado de la actividad proyectual para enfrentar el proyecto de título, o sea llega un alumno frío, los profesores de título se quejan que tienen que enseñarles aspectos que no fueron cubiertos en su formación y a mí eso me parece grave... Creo que no es malo que el plan de estudio pueda flexibilizarse, pero eso no significa que tenga que reemplazarse las fortalezas que han definido históricamente a los egresados de nuestra casa de estudios. Recuerdo talleres como Montealegre o Patiño que tenían un alto contenido de formación práctica; creo que ese quinto año era el año que marcaba, que ponía un acento profesional en los egresados.

\section{$(A G): /$}

Quiero comenzar con algunas anécdotas. Me parece que a partir de ellas puedo elaborar algunas ideas:

Una tiene que ver con un problema que tenemos en nuestro tiempo en el cual el proyecto de largo plazo tiende a desaparecer y hay un dominio creciente de situaciones a las cuales uno se ve enfrentado profesionalmente con un planteamiento de ganancias claras, aunque sean bajas, en un corto plazo, frente a lo que eran los proyectos que consideraban horizontes de treinta años... los grandes planes, y eso provoca un descalabro en el modo de entender la realidad...

Otra es una experiencia en que me tocó ser parte de la comisión examinadora que se desarrollo en el Instituto de la Vivienda donde se armó una suerte de taller de opciones de arquitectura en el trabajo directo con el usuario, es decir, tanto en la realización del proyecto, diálogo constante, cuestión que ya se había probado en algunos talleres de participación, como en el tema de que una vez que está entregado a la obra, el usuario hace cambios, hace adecuaciones, tiene problemas de daño, en fin. Entonces se instaló una oficina de arquitectura, muy controlada, dentro de un conjunto residencial a cargo de dos alumnos y se probó lo que podría llegar a ser el arquitecto, como en el caso del médico, el médico de la familia. La experiencia me parece significativa, porque lo que está abriendo son campos que no estaban siendo tratados.

Coincido, por ejemplo, en lo que tú planteabas Albert Tidy, respecto al tamaño de la demanda real, por una parte, lo cual significa varias cosas, en primer lugar, más allá del tema del proyecto de título, hay un problema serio en cuanto a que no estamos tan seguros que el alumno una vez que se enfrenta al proyecto tenga una sensibilidad lo suficientemente desarrollada como para entender una realidad que está cambiando constantemente, que se está haciendo cada vez más compleja y donde, entre otras razones, está definiéndose un rol del arquitecto distinto al que él conocía y al cual lo estamos preparando en los cursos...

Otro tema tiene que ver con los cambios en el alumnado, que nosotros vamos notando año a año. Efectivamente, la persona que llega a nuestros cursos no es el mismo hoy, es notable que el alumno está leyendo más. Cosa importante es que al final del curso estamos tratando de llegar no a la prueba final sino que a un documento de trabajo, a un papery es notable la cantidad de aportes que hacen, en incursiones en campos que son distintos a los que está recibiendo en taller. Los alumnos empiezan a investigar, directamente en la realidad... empiezan a investigar cuestiones como, por ejemplo, la inadecuación de proyectos de edificación en altura en predios que habían sido marcados por la edificación de uno y dos pisos, o los problemas que hay en la ocupación de áreas de uso público, el cierre de la continuidad de la ciudad, por ejemplo, citando casos de estudios que se han hecho recientemente. La arquitectura que el alumno está viendo en el entorno sigue patrones que no tienen nada que ver con la formación que él está recibiendo en la teoría, o sea el tema de la relación entre lo que él hace, lo que él aprende y esa realidad circundante que de ninguna manera lo desmarca...

Otro tema alude al trabajo de una alumna que entregó un documento que me pareció brillante, discute a partir de un cuento de Borges, donde se inventa un país que no existe y se publica una enciclopedia sobre ese país que no existe, el tema de la discusión de la realidad como va siendo marcada, es decir, la definición del barrio cuando no existe el barrio, donde se aplica una norma de diseño, de evaluación, de diagnóstico, que en realidad tiene que ver con un contexto que no es real, o es imaginario. Un alumno que está 


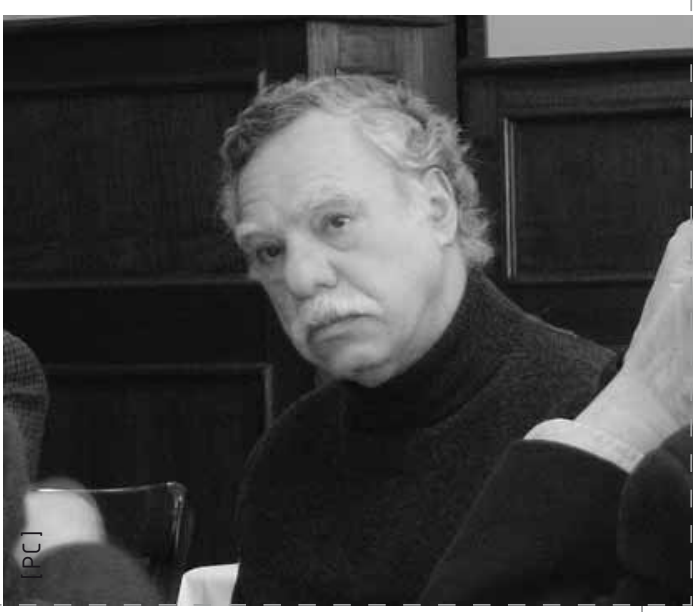

capacitado para eso creemos que está en mejores condiciones de lo que estaba hace unos años, estamos realmente entusiasmados y en el diálogo de los profesores de la línea efectivamente, se está produciendo un cambio.

El caso que se citaba de Dalcahue es un caso que se repite en muchos lugares, donde el arquitecto no solamente asume el papel directamente profesional con respecto a un trabajo puntual, sino que tiene que estar cambiando constantemente y se convierte en un personaje significativo, tanto así que logra marcar el lugar de una manera distinta... En el caso de Chiloé es notable, un grupo de alumnos egresados de esta escuela fundó un colectivo, donde integro gente de la línea de psicología, medicina, etcétera y se instaló en Chiloé y desarrolló una experiencia que no es brillante, pero que provocó cambios tan importantes que hasta llegaron a dar cuenta de formas nuevas. Creo que se están produciendo salidas..

Otra cosa importante es que, efectivamente, si bien estamos convencidos de que hay que tratar de especializar entendemos que es necesario generar una formación que sea por lo menos de un grado de homogeneización que permita evaluar.. Ahora tampoco me parece, y en esto coincido con Juan, que el tema sea mesurable en una última prueba, porque depende también de la postura que el alumno tenga... hemos discutido mucho, frente al proyecto de título, que el planteamiento teórico respecto al proyecto no es lo suficientemente desarrollado creo que eso está cambiando.

Otra cosa es frente a la cuestión de la norma, nos parece necesario que los alumnos la conozcan, pero no tienen por qué ser especialistas, incluso pueden sobrepasarla si lo justifican, es decir, lo que queremos de un alumno persona, en una visión ideal, es una persona que tenga no solamente una formación básica suficiente como para poder seleccionar distintas opciones a lo largo de una vida que, evidentemente, lo va a enfrentar a situaciones de cambio mucho mayores a las que conocemos, sino que incluso sea capaz de transformar el mundo, al menos en el área que le toca intervenir.

Por último señalar que durante mucho tiempo en el Departamento de Urbanismo se ha discutido la posibilidad de proponer a la Facultad la creación de una Escuela de Urbanismo... la Facultad se llama "de Arquitectura y Urbanismo" y nos pareció en algún momento y nos sigue pareciendo, que podría llegar a ser necesario permitir la especialización dentro de la carrera de arquitectura, pero también crear una línea distinta, una escuela que permita una mayor transversalidad que no se produce en este momento por distintas razones. Una línea que permita dialogar con otras disciplinas y al mismo tiempo que permita probar nuevos campos que en este momento no están siendo lo suficientemente abiertos.

\section{(LG) : /}

Gracias Alberto... le ofrezco la palabra al arquitecto, profesor e investigador de la Escuela de Arquitectura de la Universidad Nacional del Litoral de Argentina, Profesor Miguel Vitale, por favor.

\section{(MV) : /}

Como ustedes sabrán, por no ser de aquí no conozco en profundidad y exactamente como se articulan los currículum en la Universidad de Chile y en la Facultad de Arquitectura en especial, pero escuchaba con atención lo que se fue diciendo a lo largo de estas breves exposiciones y voy a referirme a algunas palabras anotadas, que fueron surgiendo, casi todas claves: flexibilidad, estrategia formativa, adaptabilidad, currículum más abiertos, diversidad, entre otras.

No son palabras que estuvieran ausentes en nuestra institución cuando, hace un tiempo, estábamos pensando la transformación curricular, de hecho la hemos podido llevar adelante o la estamos Ilevando adelante sobre estos mismos conceptos.

De lo escuchado, me da la sensación que se cruzaron distintas cuestiones: por un lado, en uno de los discursos que se sostuvieron, se marcaba una diferencia entre, qué es lo que se puede hacer en la titulación de grado y si eso no significa revertir en parte la problemática de la formación en el proceso, es decir, no llevar toda la expectativa de la graduación de un alumno a su última etapa de la titulación de grado.

Desde mi punto de vista creo que es muy significativo que se vea esa relación, no cargar las tintas concentradamente en ese punto final, sino que considero, al menos fue nuestra experiencia en la FADU-UNL, comenzar a ver desde la formación inicial la transformación curricular de nuestra facultad, no se introdujeron transformaciones al inicio en los últimos niveles, se implementaron más recientemente, luego de trabajar seis años en los niveles inferiores. Nuestra preocupación no se inició en el tramo final, sino que empezó, en mi caso particular, en la docencia de prime año, continuando más adelante con mi tarea docente en tercero y cuarto año.

Considero que una formación universitaria no debe proponerse sin revelar o explicitar a qué refieren las palabras que forman el léxico de los nuevos paradigmas, si es que ustedes me aceptan que lo diga así, tengo cierta desconfianza de decir, tan abiertamente, "estos nuevos paradigmas", sin acordar sobre su sentido. Es esta otra cuestión que se deslizó en las exposiciones, que merecería otro tiempo de opinión.

Volviendo sobre el eje de este foro de titulación, sobre sus contenidos e implementación, en los orígenes de la FADU, la titulación, implementada a través de lo que denominamos Tesis Final, se planteaba como un proyecto de arquitectura; hoy está abierta a la posibilidad, más aceptada en general por 


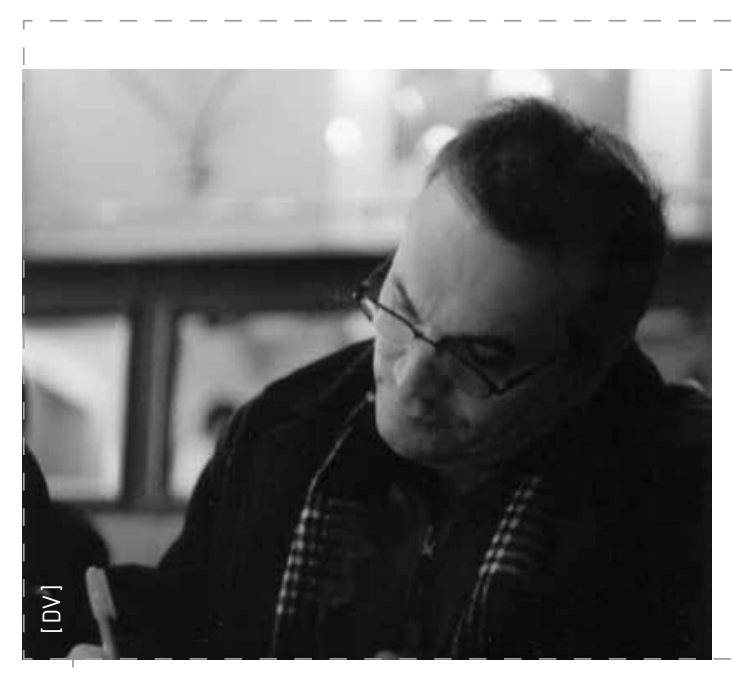

los alumnos, que un trabajo de tesis pueda incluir una propuesta proyectual, pero que no necesariamente sea un proyecto de arquitectura como edilicia, en general, la tendencia de los alumnos es conceptualizar el proyecto de arquitectura en relación con la capacidad de hacer ciudad y sus vastas implicaciones.

El proyecto cargado justamente de una mirada urbana, marcando las preocupaciones que se dijeron anteriormente, por un lado; por otro, hemos retomado algunos docentes del área de proyecto, el debate sobre la distancia que existe entre lo que entendemos como el proyecto y la proyectualidad; es necesario diferenciar lo que creemos igual y no lo es,... no me detengo ahora para no extendernos, pero sucedía más o menos lo mismo en nuestras primeras reuniones.

Hoy se han cruzado dos términos que para mí no son sinónimos y sería bastante importante despejarlos: una cuestión es generar una formación abierta y otra es generar una especialización, a mi entender, y lo digo porque he sufrido bastante discutiendo con colegas en mi institución, es más importante generar una formación abierta antes que una especialización.

Podría dar un ejemplo tal vez rudimentario, pero que puede ser interesante,... nombré esas primeras palabras claves y el profesor Jorge Lobos las presentó en su alocución para repensarlas, porque de una u otra manera emanan de directivas Institucionales: currículum que se adaptan a una universidad en la que hay que pagar y que en general muchos de estos términos provienen de documentos externos a los intereses de la institución, llegando como condicionantes, justamente, para que se produzca esa rentabilidad de la institución,... No hay que dejar en el vacío esas palabras, entonces cuando hablamos de un mundo en transformación, de un mundo que ha perdido los paradigmas, una arquitectura en crisis, de un profesional que se enfrenta a una diáspora,...se ha abierto el panorama.
Lo que nos propusimos, replanteando posiciones desde primer año, fue tratar de ser muy conscientes de qué queríamos decir cuando hablábamos que se ha caído un paradigma o qué es lo que significa afirmar que las transformaciones superan el propio acto de poderlas seguir, pareciera ser que están siempre más adelante; en este sentido lo que hemos acordado es proponer cambios en un movimiento de transversalidad, como lo planteaba en su exposición el profesor Alberto Gurovich.

Estamos desarrollando una carrera que tiene un fuerte movimiento transverso, el currículum es muy tramado, los cambios se dan desde muy abajo, es importante la aparición de los saberes transversales, sea por el mecanismo de las materias optativas o por propias modificaciones de programas de materias básicas, que se han ido implementando desde primer año hasta el último nivel.

Se estaría demostrando en principio que lo conveniente, en nuestra experiencia, es más que a la especialización aportar a la formación abierta, en tanto que si observamos algunas estadísticas, cuando referimos a los cambios que se producen en el mundo, no se alcanza a escribir un documento cuando ese cambio ya fluctuó, significando, un cierto riesgo el pensar que la especialización pueda responder, en cierto modo, a políticas de mercado que se pueden instalar, dado que esas políticas, en el mercado pueden desaparecer en tres años, encontrándonos en la situación de haber puesto las líneas académicas, en formar desde una especialización que el mercado puede desestimar en un breve plazo... las transformaciones son, en general, variables de tres a cuatro años.

Si se centra demasiado el interés en la especialización, el riesgo que se corre es que el profesional caduque en sus niveles de conocimientos y en la prestación social que pueda hacer en muy corto tiempo, mientras que, con el concepto de formación abierta lo que estamos generando es un profesional que puede retroalimentar más fácilmente sus estructuras de conocimientos, sus sistemas operacionales y su conexión con el medio, que lo habiliten, no a una especialización que clausura otras posibilidades, sino que diría... y quiero usar con un tono de seriedad la palabra estrategia,...un profesional más estratégico, que puede captar mejor las relaciones con su medio y moverse sin la desesperación de pensar que el mercado lo está superando... hasta aquí lo que me parece puedo aportar, perdón si me desvié del temario, traté de seguir el hilo de las palabras que rondaron la mesa.

\section{$(L G): /$}

Tomé nota de algunas de las cosas que se dijeron y creo que hay una serie de temas muy interesantes.

Se dijo: el proyecto como método fundamental de formación y aprendizaje, que hoy es mirado como una instancia de alta productividad por otras profesiones. Se dijo o se caracterizó al proyecto de título como una instancia explorativa y propositiva más que como una instancia de habilitación profesional... planteando la instancia de habilitación más relacionada al quinto año.

El tema de formación continua que replanteó el profesor Tidy, no hay que ver el proyecto de título como una instancia final. Se planteó en un momento determinado, recuerdo, el profesor Cárdenas en alguna de sus actividades como director de la escuela de posgrado, la formación continua como un absoluto de nuestra escuela que se ha ido dejando de lado...

El proyecto de título y la discusión de proyecto de título obliga a la discusión del plan de estudios, abordarlo efectivamente, incorporado en una malla, como dijo el profesor Montealegre... la formación básica como una exigencia mínima, necesaria, que no 
se debe perder en una visión formativa, desde la flexibilización.

Algo importante, nuestros alumnos: nuestro rol como formadores de alumnos que son efectivamente entes culturales, que llevan un proyecto de desarrollo en sí mismos, y la Universidad como potenciadora de aquello...

Yo diría que por último que este alumno que hoy día tenemos y que desatacaba el profesor Gurovich quizás no es diferente al que era antes, pero hoy día quizás nosotros somos más conscientes de ello; un alumno con una gran capacidad de gestar desde sus propios intereses su formación, un hombre que está más enfrentado hoy día que antes a la autoformación, que esta información que antes entregábamos, el alumno las encuentra mucho mejor en otras partes. Nuestra capacidad y requerimiento para acoger estas modificaciones y darles espacio en el proyecto de título como culminación de una formación abierta, antes de una especialización, pero que dirija los intereses.

Éstas son ideas con las que me quedé. Todas ellas van más allá del tema específico de discusión y me hacen pensar que el proyecto de título dentro de un marco mayor, quizás siempre lo hemos enfrentado muy parcialmente.

Ha salido a la discusión el caso de quinto año, la modificación de las prácticas profesionales, acciones puntuales que de repente hay que volver a ver dentro del marco de un programa general...

Ofrezco la palabra... Jaime.

\section{$(J D): /$}

Visualizo la titulación no sé si como lo último de la carrera o lo primero del ejercicio profesional. Más bien podríamos decir que es el umbral entre ambas, entre la academia y la profesión y que nos permite, por un lado, evaluar la formación que estamos dando y también prospectar el tipo de profesional que estamos dando a la sociedad...

Hoy día a partir del acuerdo de Bologna que ha significado la gran reforma europea, se ha introducido un concepto que parece nuevo, pero que no lo es tanto, el concepto de empleabilidad; éste tiene que ver con aquellas competencias que el medio requiere a los profesionales que formamos, y una de las competencias... podríamos enumerar una larga lista que claramente marca la diferencia entre un profesional y otro hoy día es la adapatabilidad, su capacidad de adaptarse a los continuos cambios que el mundo y la sociedad tienen, y en ese sentido es que la formación que la Universidad de Chile busca esa adapatabilidad: Primero como universidad nacional, yo diría hoy como universidad internacional, nosotros debemos ser capaces, y creo que en algún grado importante lo estamos logrando, de entregar un profesional capaz de adaptarse a los lugares y a la época donde le toca desempeñarse... el gran cambio que busca el plan de estudios de arquitectura aún no está asumido y está referido a cambiar el foco de la formación.

El objetivo del plan anterior era entregar conocimientos, si vemos el objetivo de este plan es desarrollar una capacidad de adquirir conocimientos, que es algo muy distinto, y en eso nuestros egresados pueden dar fe que el conocimiento hoy día no se entrega en las universidades, pero si metodológicamente desarrollamos esa capacidad de adquirir conocimientos. Ellos van a tener las herramientas necesarias para desempeñarse, como lo están haciendo, en cualquier lugar del territorio y del planeta... yo tengo contacto y conocimiento de egresados nuestros que ejercen desde Caleta Tortel hasta Nueva York o Londres y ninguno de ellos ha manifestado no poder desempeñarse sino por el contrario, se desempeñan con bastante éxito, en grandes oficinas norteamericanas o europeas, o en pequeños estudios privados o en entidades públicos de nuestro territorio.
Entonces creo que por ahí hay un concepto que debiéramos reforzar y estoy de acuerdo también que la flexibilidad no garantiza la diversificación y que la diversificación es distinta a una especialización, la especialización es muy difícil de obtener en un pregrado, es más bien una labor de posgrado, que hoy día son casi una obligación, una necesidad de continuar estudiando y en ellos los profesionales podrán ser más específicos, pero no es posible pretender que en cuatro o cinco años se entregue toda la formación básica y además se transformen en especialistas con el grado de eficiencia que necesitamos. Por último quiero rescatar una experiencia que existía en nuestra facultad, que posteriormente desapareció por razones circunstanciales y que hoy día creo que reaparece con fuerza: las prácticas profesionales... éstas obviamente no tienen por función una formación de tipo académico, sino es la primera vinculación con el medio, absolutamente necesaria en cualquier profesión. Sabemos que en otras latitudes antes de otorgar el título, que es la autonomía para ejercer, se les exige dos o tres años de experiencia práctica a los estudiantes y nosotros no tenemos esa exigencia entonces lo mínimo es otorgarles la posibilidad de un contacto de, al menos algunos meses, en un medio profesional y la experiencia reciente nos dice que ha sido altamente beneficioso para ellos este contacto... esa carencia formativa que mencionaba Albert Tidy creo que perfectamente puede ser asumida por los talleres de tercer y cuarto año si realmente cumplieran los objetivos que se les han encomendado; parece redundante un noveno taller cumpliendo esa labor tan específica... me parece más valioso entregar ese tiempo a un encuentro con la realidad.

\section{(AM) : /}

Yo quería hacer un comentario sobre algunas ideas que se han dicho acá. En primer lugar creo que, en una visión de escuela de 


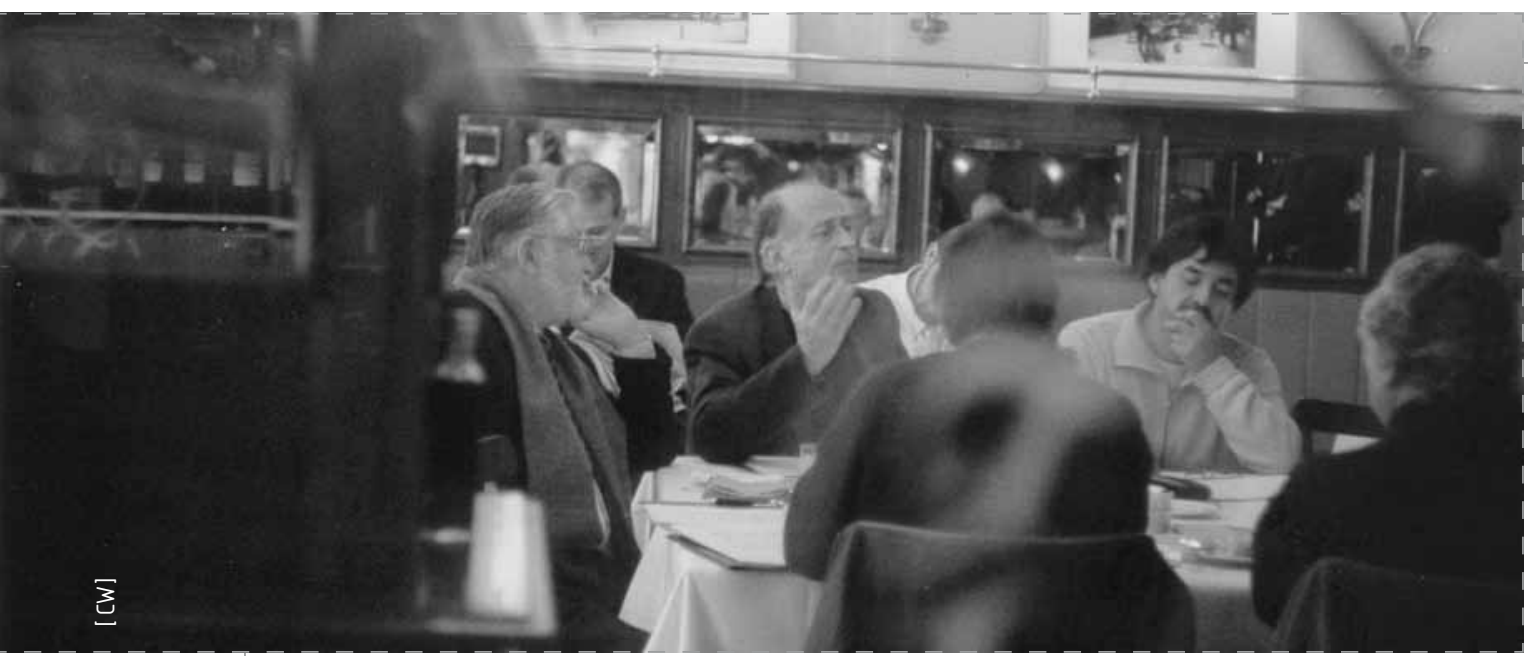

arquitectura, no se trata de un enfrentamiento entre lo que Albert Tidy llamaba el Beaux Arts y la teconología. Me parece que más bien el problema en nuestra escuela, más que de un enfrentamiento se trata de que, en general, no hay una integración de la parte tecnológica a la formación del Beaux Arts, que sí está funcionando y que hemos heredado.

Por otra parte la palabra especialización de repente aparece como una palabra fea, una mala palabra que no debiéramos mencionar en el ambiente universitario.

En la época de Aristóteles la física era parte de la filosofía, toda la gama de los conocimientos humanos era filosofía. Hoy día se han abierto distintos campos. El urbanismo se podría tomar como una especialización, pero también bajo un punto de vista netamente universitario. Entonces esa es verdaderamente una rama, y lo es a tal punto, que recién Alberto Gurovich nos acaba de plantear que podría haber una Escuela de Urbanismo.

Cuando hablo de especialización me refiero a todos los campos que se están abriendo y que generalmente se desprenden de la Arquitectura. Una buena formación del arquitecto debiera dar una muy buena base para entrar en ellos. Sin embargo se le están escapando al arquitecto y están siendo tomados por otras profesiones. No conozco oficinas de arquitectura que sean expertas, por ejemplo, en problemas de medio ambiente.

Esta especialización, estoy de acuerdo, no se puede dar en el marco de los seis años de estudio de arquitectura. Pero creo que tampoco es necesario crear escuelas de urbanismo, escuelas de ambiente e ir creando una escuela para cada una de las especialidades. Estas especialidades deben ser mostradas bajo un ángulo y bajo un punto de vista universitario. ¿Qué significa un punto de vista universitario? La propuesta de la especialización no está dirigida a la idea de formar un Tecnológico. La idea al respecto significa mostrar estos campos bajo un punto de vista amplio, universitario, de tal manera que el alumno entienda, en general, de qué se tratan y sepa de qué mundo estamos hablando.

Me parece que en el argumento del éxito de ciertos alumnos, hay como una autosatisfacción que no la encuentro buena. Es como una especie de defensa, de los medios universitarios frente a los medios profesionales. En el ejemplo de que un alumno sea exitoso en Tortel o en Nueva York no tengo de donde estar seguro que eso pueda atribuirse a una especie de formación abierta que demos en la Universidad de Chile. Lo que veo, generalmente, son casos de gente que ha tenido que ser autodidacta en su tema, porque la Universidad no le ha dado nada especial de preparación para actuar en esos campos. Ha tenido que improvisar, ese alumno exitoso, y quizás es exitoso sencillamente, yo diría, por una cuestión de coeficiente intelectual personal.

A lo que voy es al qué podemos hacer como escuela para ir mejorando la formación de nuestros alumnos. En ese sentido yo quisiera decir que me siento, a pesar de ser una persona que se desempeña principalmente en el campo profesional fundamentalmente un universitario. ¿Porqué me siento un universitario? Porque en realidad me interesa entender el por qué, cuál es la razón por la que estamos haciendo las cosas, no quiero aprender a hacer cosas, no quiero aprender a solucionar, por decir algo, una cortina o una cubierta. Quiero entender por ejemplo, cuál es la física que conduce a determinadas soluciones.

En ese sentido de formación universitaria yo echo mucho de menos en la escuela una serie de cursos de formación humanística que han ido desapareciendo y sí que están en esa perspectiva de formación abierta. En nuestros cursos de iniciación, no sé si nos faltan otro tipo de materias, no sé si de sociología, por ejemplo, que preparen precisamente a los alumnos para tomar esa actitud de líderes en provincias o cosas por el estilo. No me siento satisfecho con lo que estamos haciendo y veo, y por eso partí haciendo una especie de diagnóstico de lo que es nuestra realidad. Veo que la cuestión no está funcionando, veo que arquitectura es una carrera que se está desprestigiando. La gente ya no quiere estudiar arquitectura y resulta que nosotros pensamos que sí está funcionando perfectamente bien. Creo que no, creo que tenemos que volver a una formación mucho más universitaria, mucho más general. Pero también tenemos que tratar de penetrar toda esta serie de ramas en las que la arquitectura, de alguna manera, está avanzando y que nosotros las dejamos desprenderse de nuestro tronco por esa especie de adoración al arquitecto diseñador. Resulta que la arquitectura también tiene una serie de factores científicos, técnicos, que le dan una especificidad y una capacidad de desarrollarse en el mundo práctico.

\section{$(J C): /$}

Sucede lo que se temía que tenía que suceder, en una reunión de arquitectos, el tema era el proyecto de título, la instancia de titulación y estamos cuestionando el plan completo, la formación profesional... etcétera.

\section{(AM) : /}

Es que el título no es el problema...

\section{$(J C): /$}

Espérate, que algunos profesores manifiesten satisfacción por la formación de nuestros alumnos porque tienen éxito aquí y allá... y que hayan otros profesores que sienten insatisfacción porque al otro lado del mesón encuentran a un colega ex alumno en quienes cifraban expectativas de desarrollo en otra área y que está realizando una labor que en cierta manera más que satisfacción siente menoscabo... el profesor Gurovich se queja 


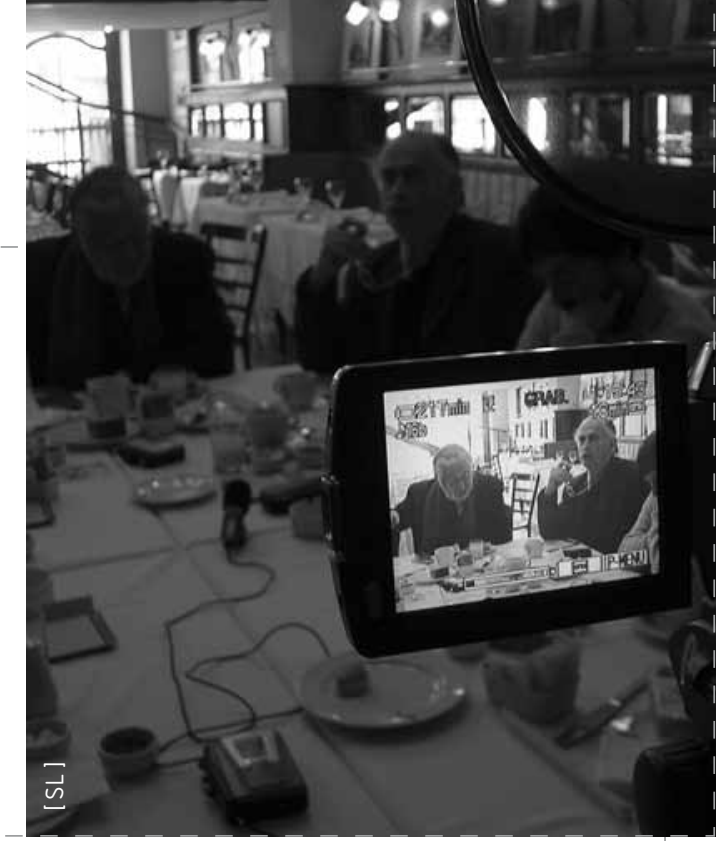

de que los alumnos no tienen una capacidad desarrollada de sensibilidad frente al medio para poder captar los cambios, para poder adaptarse a las situaciones, y esto debiera ser muy importante en una universidad nacional.. pero se olvida que en esta escuela todas las disciplinas de tipo humanístico que permiten hacer una aproximación al estudio del medio social fueron borradas de nuestro currículum y nunca nadie a vuelto a decir "mire qué pasa, por ejemplo, con sociología urbana, entre otras disciplinas, entonces efectivamente conocemos los problemas que tenemos, pero no entregamos los medios con los cuales resolverlos... ahora yo no estoy tan contento como mi amigo Alberto..

\section{(AM) : /} (risas)

A ver profesor, aclaremos bien las cosas

\section{$(J C): /$}

...Es efectivo, como dijo Alberto Montealegre, hay profesionales que podían no haber pasado por la facultad y van a ser siempre autodidactas y van a tener éxito... pero yo estoy seguro que el transcurso de seis años en la Universidad les ha permitido precipitar sus capacidades y poder desarrollarse con el brillo que lo están haciendo... la autosatisfacción tiene de esto y de lo otro. Nosotros también tenemos que referirnos a un tema que ha estado ajeno en esta discusión: el proyecto de título...

...Uno de los elementos básicos de este proceso son los alumnos, los profesores de título sistemáticamente han traído a colación en cada uno de sus debates, las deficiencias que los alumnos presentan en el manejo de sus habilidades, de conocimientos básicos, y cuando esto se ha planteado, generalmente el argumento con que se retruca es que "como puede decir eso profesor si de todos los premios CAP la Universidad de Chile ha ganado tantos y en tantos otros proyectos los alumnos han logrado muchas distinciones".

\section{Autocomplacencia.}

Yo no digo que adoptemos la posición flagelante, pero si pido objetividad cuando se analizan las cosas... yo traje aquí antecedentes que vienen del año noventa y hay anteriores, (el año noventa el profesor Bendersky me mandó una nota en que un profesor con toda la trayectoria que él tenía se sentía apesadumbrado con el nivel en que sus alumnos abordaban el sexto año como unidad y eso ha sido repetitivo porque nunca se ha vuelto a plantear este tema). Esto de hablar de especialización o diversidad, creo que nuevamente estamos en un medio poco claro, ¿dónde empieza una y termina la otra?

Creo que esta facultad, debiera tener como objetivo del ciclo básico, en el pregrado, la formación de un prototipo que corresponda al perfil definido como objetivo central de la malla curricular e incorporar vía los cursos electivos algunas de las proyecciones que son necesarias o que están requiriendo respuesta en el medio profesional dependiendo de la naturaleza y urgencia, es como la escuela debiera asumir los cambios que la sociedad le va planteando y eso creo no puede tocar el núcleo central de la formación, tiene que ser motivo de los postítulos o de los posgrados, que se pueden renovar, que se pueden actualizar, que tienen esa dinámica y debiera ser el frente en el cual la Universidad responde a estos desafios... los planes de estudio del ciclo básico, como se dijo, deberían ser por lo menos de una generación para que puedan ser efectivamente evaluados... entonces aparece con fuerza un ciclo de educación continua como un elemento estructurante de nuestros planes de estudios, la formación requerida por el medio no está completa en sexto año, y menos aún... si atendemos a que el campo profesional es cíclico... aquí hemos hablado del profesional que está detrás del mesón o que está en el servicio público... debo recordarles que por más de treinta años el medio natural del ejercicio profesional de la arquitectura se dio en los servicios públicos y nuestra facultad formó arquitectos que le dieron prestigio a su labor, hoy por hoy se ha reestructurado el medio y todo esto sale al campo privado, no se sabe si el día de mañana esto podrá volver atrás.

Ahora quiero señalar otro aspecto que me parece importante... la práctica profesional.

Según lo dicho por un profesor, no constituye experiencia académica, difiero de esa aseveración, creo que se retroalimenta, creo que ahí hay un proceso casi dialéctico en la formación del alumno, el conocimiento de las técnicas, de los materiales, de los procesos constructivos potencian la capacidad proyectual de los alumnos; hoy el alumno dibuja y en ese medio, que es nuestro lenguaje, no hay consistencia que sustente posteriormente los proyectos; distinto sería si efectivamente como un proceso natural que se inicie en primer año, como se les enseña estabilidad uno, estabilidad dos, tres, o construcción uno, dos, tres, cuatro, hubiese efectivamente ese contacto con el proceso de la construcción, cómo la arquitectura se hace real... nuestros alumnos, no saben distinguir que representan, cuando dibujan dos líneas paralelas de un milímetro, de dos milímetros, de tres milímetros, entonces sus capacidades proyectuales se disminuyen porque el campo de opciones técnicas se reduce, ven revistas y quedan con sólo la opción de copiar, pero sin saber como se puede hacer aquello, de qué está hecho, en consecuencia creo que la práctica profesional a nivel de quinto año es una opción para que el alumno se vincule con el quehacer profesional más que con el proceso mismo de proyección... entonces mi postura es que esta práctica debiera estar íntimamente ligada con los procesos formativos desde el primer año, como práctica de construcción y remata en práctica profesional en quinto año. 


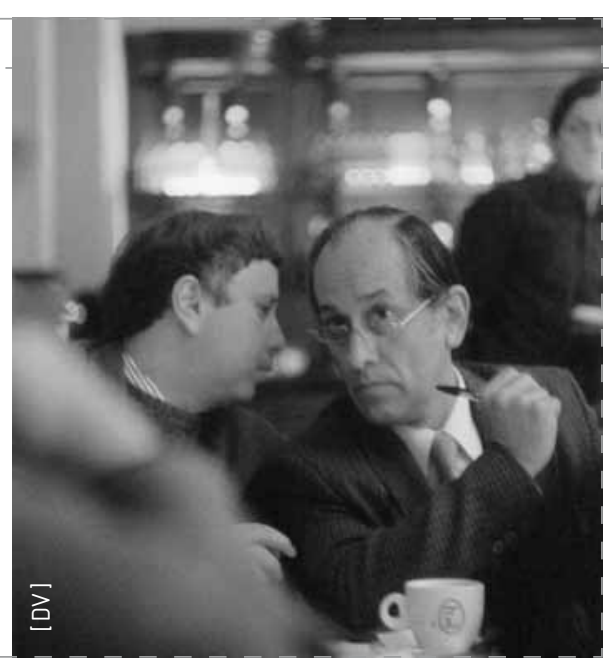

\section{(AM) : /}

Lo que hemos dicho es que el proyecto de título es una instancia que está íntimamente relacionada con el Plan de Estudios, con un plan de formación completa. Entonces hablar del proyecto de título, así en abstracto, sin hablar de lo otro, a mí se me figura, haciendo una comparación, que en un barco, como es la Universidad de Chile, que está caminando, que tiene una cierta inercia, que sigue avanzando, pero que está deteniendo su marcha, que está en cierta manera desacelerando su ritmo, hablar de Proyecto de Título en sí mismo es como ponernos a discutir el menú del almuerzo, en vez de verdaderamente preocuparnos del barco completo. Digamos... no tiene tanta importancia qué vamos a almorzar mañana, el problema es cómo está el barco y creo que eso es lo que hemos estado discutiendo y me parece bien que lo estemos haciendo y ojalá que una cosa como esta reunión, que debería ser normal en nuestra facultad, se transforme en algo frecuente, aprovechando este buen ambiente.

\section{$(J L): /$}

Quiero retomar el tema del proyecto, como sistema pedagógico, porque, como planteaba Jaime, es una de las fortalezas de la escuela. Todos lo sabemos... Pero a su vez, una de las crisis del proyecto es la tendencia a evaluarlo solamente como diseño, y recordemos que ésta es sólo una de las variables de la arquitectura. Por otra parte el proyecto se desarrolla sólo en los talleres, no es una práctica general a los otros ramos, exceptuando urbanismo.

En consecuencia me llegan alumnos de quinto año, que saben perfectamente diseñar una imagen computacional, pero que no distinguen claramente las dimensiones de un ladrillo o de un bloque de cemento, no saben cuáles son las propiedades de uno o de otro, nunca los han tomado en la mano.
En cuarto año me llegan alumnos que no saben dibujar, entonces el proyecto si bien es una de las virtudes de la escuela, se maneja parcialmente, sólo en el taller.

De acuerdo a esto quiero terminar con dos paradojas:

Primera: Tema; vivienda social. Un alumno, decidió no diseñar una vivienda social, hizo una ordenanza que se refería a uno de los principales problemas de la vivienda social; la segregación a bolsones de pobreza. Él pensó que solucionaba eso haciendo una ordenanza en que en todos los edificios del centro de la ciudad si construían, más de un diez por ciento de vivienda social en su terreno, el municipio le daría más edificabilidad. Seguramente en todas las plantas bajas, que eran las plantas menos vendidas, podría instalarse vivienda social. Podían estar en Las Condes, en Vitacura, en Ñuñoa, en Santiago...

Otra paradoja; cuarenta y nueve por ciento de los proyectos de título son del área social y principalmente del área cultural. El diseño de Museos es tradicional en esta escuela. Sin embargo un alumno seguramente lo va a hacer peor que los arquitectos especializados, que han diseñado muchos museos, porque lo va a hacer solo... los museos jamás se hacen por una sola persona, en ellos trabajan decenas de profesionales...

Hay un error manifiesto en el tamaño de los proyectos de título, que contribuye a distorsionar el proceso de enseñanza.

Las preguntas son: ¿qué nos sirve más: ese alumno que puede escribir una ordenanza y está transformando positivamente la realidad, o el alumno que sigue intentando diseñar un museo solo...? ¿Quién transforma más la realidad, un alumno que puede descubrir un material que soluciona los problemas de vivienda social del país o un alumno que se pone a diseñar una vez más una vivienda social?
Última pregunta: si se nos presenta un alumno de título con una ordenanza ¿es aceptado o es rechazado?, ¿lo reprobamos o lo aprobamos con distinción máxima?..

Si alguien quiere me contesta o si quiere sigue hablando (risas).

\section{$(A G): /$}

Tienes razón, Jorge... hay un problema muy serio que tiene que ver con las comisiones, quiénes las constituyen, cuál es el criterio con el cual evalúan e incluso qué tipo de preguntas se le hacen al alumno y cómo lo están midiendo... efectivamente yo creo que ese es un tema que debiera estar discutiéndose. En este momento el tema de las tesis genera un punto de crisis que vamos a tener que resolver, en la realidad, ¿quiénes van a tomar exámenes en las tesis? y ¿cómo se van a tomar exámenes?, qué tipo de preparación es necesaria... deberán existir profesores informantes, etcétera..

Otro tema, para nosotros muy significativo, es el tema de la creatividad; efectivamente si uno hace un corte de los proyectos que nos toca evaluar hay un problema que va más allá de lo que el alumno está superando o resolviendo, hay un tema de creatividad. Es decir, el tema de la flexibilidad del diseño: hoy día parece ser una cuestión esencial para resolver las contradicciones que tiene la ciudad y hay un choque entre la flexibilidad solicitada y los problemas de la rigidez que generan, por ejemplo, las normas o en fin, una arquitectura que sea distinta implica también la capacidad de síntesis, y un conocimiento de cuestiones esenciales como la habitabilidad, más que la forma de resolver a través de un determinado material, pero entender aquello, implica saber relacionarse con la realidad.

Hay muchas lecciones que recibe el alumno, no solamente en las clases, no solamente en las prácticas, sino que en el contacto con la realidad cotidiana: circula por la ciudad, sale de la ciudad, y va absorbiendo 


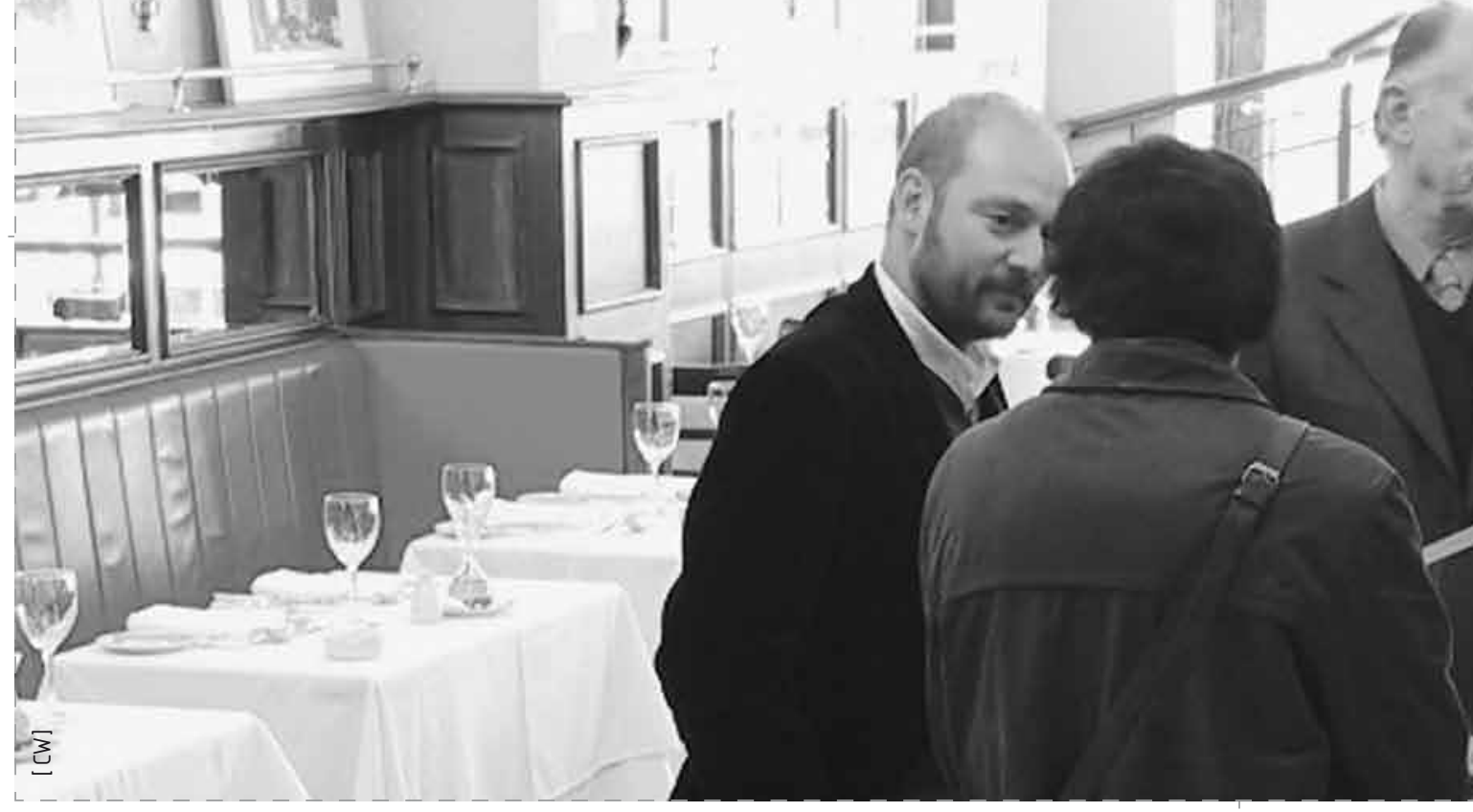

una cantidad de información que en realidad aparece de repente un poco incoherente si no se ve críticamente...

Vamos a dar una vuelta y yo vengo a presentarles la cantidad de dormitorios sur que hay en la solución corriente de los edificios que se están construyendo y si el alumno llega a taller con esa solución evidentemente que va a tener una baja nota; entonces el contraste con la realidad circundante en la cual, si bien se enriquece, también es una experiencia contradictoria...

Hay una serie de problemas que tienen que ver con la visión de defensa cerrada del gremio también frente a una realidad que se ha diversificado y que implica un juego de roles que no se están cumpliendo.

Echo de menos algo también importante: que en el ámbito de la escuela pueda existir algo más que una simple referencia, una suerte de taller de simulación en el cual se puedan tender a construir modelos, porque efectivamente si no manejamos el tema de los modelos cada vez va a ser más difícil adaptarse al medio.

Por último, otra cosa, que hoy día, con el proceso de autoevaluación, ha quedado en evidencia, es que sale el egresado, sale el titulado y perdemos contacto con ellos y yo creo que necesitamos hacer un seguimiento constante porque eso retroalimenta nuestra propia formación. Eso que se dice de casos particulares, de contacto con alumnos, tiene que generalizarse. Tenemos que saber cuál es el resultado de la acción de un programa, el resultado que se genera efectivamente.

\section{$(J C): /$}

Varias cosas... me refería al sexto año, al tema de las comisiones que tú tocaste recién, Alberto... creo que es importante otorgarle un rol claro y específico a las comisiones y hacer un perfil de quienes debieran formar parte de estas comisiones de acuerdo al objetivo que se le asigne al examen del proyecto de título, que va a ser distinto si esta instancia se constituye en la evaluación de todo el proceso formativo de la carrera, o si es un examen especifico de titulación en sexto año, para lo cual lo anterior deberá haber concluido en $5^{\circ}$ año...

Otra cosa tiene que ver con cómo nosotros calificamos, o el marco con el cual vamos a calificar a nuestros alumnos... los proyectos de título son individuales y por ende cada alumno se compromete con un tema, define una situación particular que le interesa, y esto da una diversidad enorme... los profesores de sexto tenemos cinco o seis meses de trabajo con los alumnos, podríamos decir que nos aproximamos a conocerlos y por lo tanto podemos evaluar de acuerdo a los postulados que el alumno estableció. Tal vez debería haber un pauteo, tendría que haber algo que pudiera efectivamente acotar el examen como tal.

Hablando de las comisiones debiéramos tener claro en qué instancias y cómo se produce el proceso de rechazo, porque actualmente, tal como está planteado el reglamento, un profesor de la comisión puede rechazar un proyecto y hemos tenido esa experiencia: que un profesor se niega a aprobar porque en su especialidad y desde su particular punto de vista hay aspectos no resueltos. Yo estimo que para rechazar a un alumno que ya ha cursado cinco años de la carrera tienen que haber razones muy fundadas para poder ser rechazado, y que debieran ser la opinión de a lo menos dos miembros de la Comisión; debiera ser fundada y por escrito, los exámenes deberían ser siempre públicos...

El proyecto de título es la fiesta, de nuestra escuela, es la culminación de los procesos, nosotros debiéramos tener el foro lleno de paneles en que los alumnos estén observando cuál es el termino de su proceso formativo.

\section{$(J L): /$}

Agrego algo, ... la discusión de los profesores debiera ser pública, no tiene porqué ser a puertas cerradas. Debiera ser en el auditorio de la escuela. Si concentramos los exámenes de título en días corridos, perfectamente pueden hacerse en veinte días. Marzo sería el ideal, cuando los alumnos están entrando a la escuela y donde sería una experiencia fantástica para los de primero a quinto año, sentarse en el auditorio y ver cómo los profesores discuten y asumen públicamente, cuando rechazan o aprueban un proyecto. Sería el gran acontecimiento universitario.

Si nosotros viéramos al final del proceso todos los proyectos que fueron reprobados y los comparáramos, muchas veces, con los proyectos que aprobaron con un cuatro seguramente habrían muchos cambios. Eso es muy injusto para muchos alumnos. No sé porqué debe entregarse inmediatamente la calificación, porque no se puede esperar el fin del proceso de exámenes, se toman todos los proyectos que están en discusión y se vuelvan a ver. Sería un poco más equitativo.. no sé porque hay una urgencia de poner la calificación inmediatamente sobre todo cuando están en este punto tan conflictivo que merece una discusión mayor.

\section{(AM) : /}

Finalmente quisiera referirme a otra cosa: este problema que tiene nuestra escuela de ser numerosa, en que tomar los exámenes se transforma en una cuestión difícil. No queremos quedarnos con una enorme carga de alumnos que queden en una situación rara, que egresaron y que todavía no se titulan. Estamos dando a todos los alumnos el mismo plazo para recibirse que es de aproximadamente seis meses. Creo que no todos nuestros alumnos tienen, por configuración mental, por carácter, por toda 


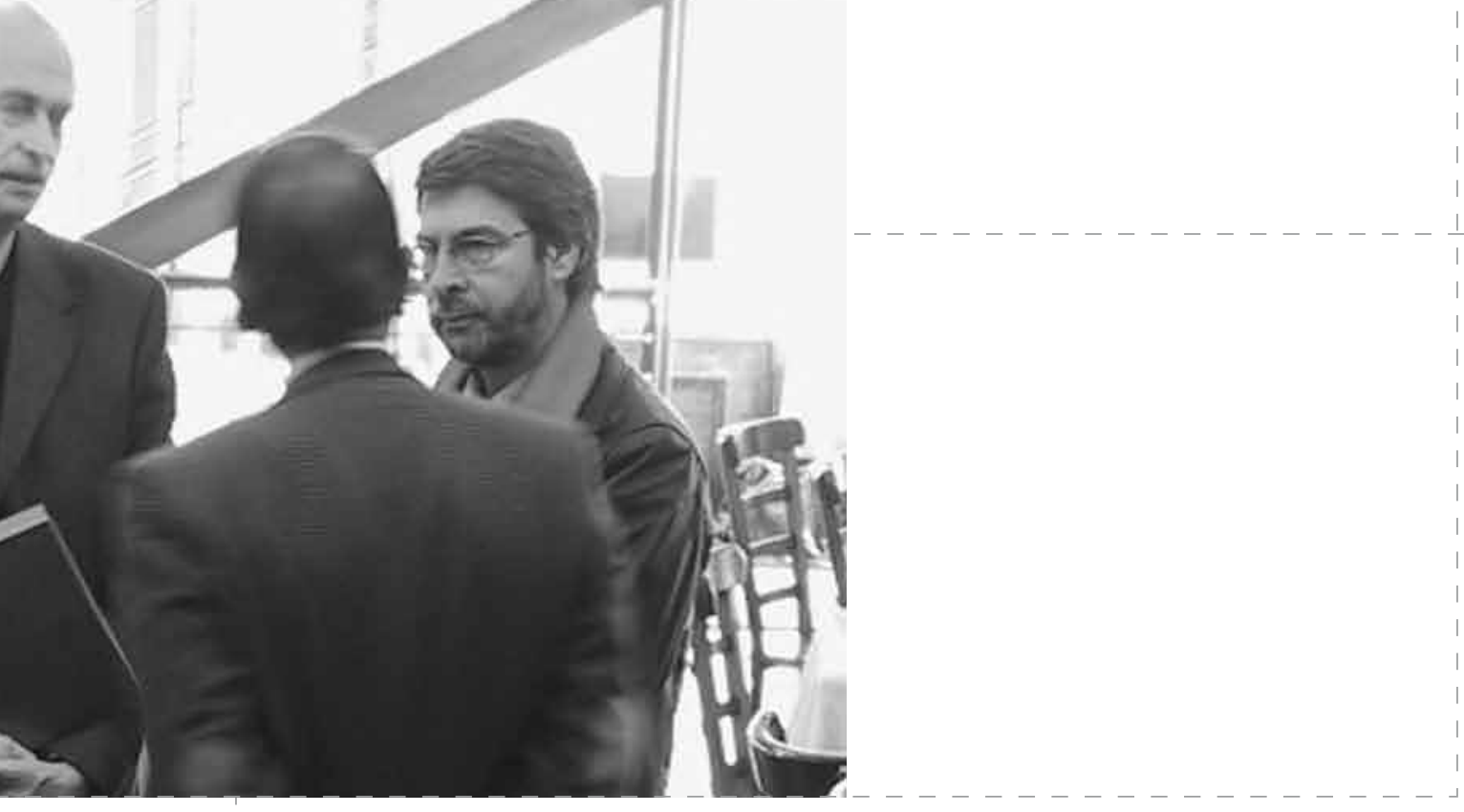

una serie de cosas, las mismas características. Hay muchos que necesitan una maduración, que no son capaces de desarrollar un proyecto de título en seis meses o que su tema es más complejo. Pienso que deberíamos dar un plazo más flexible para la titulación, reconociendo que las capacidades, que los temperamentos son diferentes. Muchos alumnos que salen, se sienten un poco desorientados y el proyecto de título es para ellos una necesaria pausa de reflexión. Resulta que si son seis meses es nuevamente una presión terrible del plazo.

\section{$(J \mathrm{~L}): /$}

A partir de eso yo pondría dos fechas de exámenes: marzo y agosto, donde comienzan los dos semestres... Si se presentan cien alumnos, en cada una se titularían cincuenta alumnos, en veinte días, es decir menos de tres alumnos por día. Esto es perfectamente posible.

\section{$(L G): /$}

Iniciamos la última ronda de intervenciones...

En realidad el tema que se ha abierto ahora es más el punto directo del proyecto de título, las comisiones, los tiempos, el proyecto integrado a un ciclo mayor y como se relaciona con las prácticas profesionales, con los seminarios, con la flexibilización del plan de estudios...

Respecto las prácticas... uno se encuentra con alumnos que tienen posibilidades extraordinarias, como participar en el hospital militar, participar en la biblioteca que se está construyendo ahí frente a la Quinta Normal; de pronto llega la opción, en un momento no adecuado del período académico, ese alumno queda cuestionado, no puede hacer la práctica ahí. Entonces el tema de flexibilidad en la etapa final quizás todavía no lo hemos asumido absolutamente en el plan de estudios... en los seminarios pasa lo mismo: investigaciones que de repente hay que terminarlas porque se acabo el plazo, tres o cuatro meses para una investigación: no es nada... es un tema complejo a abordar.

\section{$(J L): /$}

Bueno, eso tiene que ver también con una universidad pagada, cuando los chicos tienen que pagar año a año, tienen cierta urgencia en terminar sus trabajos, porque si se retrasan un año, es un año más de pago... es antinatura y antiacadémico.

\section{(JD) :/}

Debiéramos tratar en esta última ronda de adelantar algunas propuestas ya que al parecer hay conciencia de que algo debe cambiar en nuestro proceso de titulación... si con la titulación lo que estamos entregando es una habilitación profesional, lo que debemos exigir es autonomía y creo que en ese sentido debiéramos ser más flexibles en las formar de otorgar esa autonomía... si es un proyecto me parece bien, pero también hay que aceptar que para algunas personas, otras opciones también podrían ser válidas... ya tenemos el caso de las tesis para aquellos que quieran dedicarse a un trabajo más del tipo académico, pero creo que la forma de la evaluación final actualmente debería tener algunas modificaciones.

En qué sentido: aunque exista la instancia, y creo que debiera mantenerse, de un examen final con un grupo de profesores que evalúe, la única opción no debiera ser un proyecto realizado en seis u ocho meses, ¿por qué no presentar, por ejemplo, una trayectoria mayor?, es más, creo que si revisáramos los mejores proyectos de título o los mejores alumnos que se han titulado en el último año veríamos que ellos empezaron su proyecto antes, antes no formalmente, lo empezaron antes como un problema, lo empezaron en la práctica, lo empezaron en el seminario o lo empezaron con sus preocupaciones de tercer o cuarto año. Entonces por qué no podría un alumno presentar su trayectoria en la escuela a una instancia evaluadora final y recogerla en la forma, por ejemplo, de un portafolio, que en el medio profesional es una práctica habitual... hoy día tenemos tecnología como para poder hacer más viable ese portafolio... en el proyecto MECESUP ${ }^{1}$ de nuestra Facultad, que se trata de mejorar la docencia incorporando tecnología digital a la formación. A partir de este año se desarrollarán bases de datos para que los alumnos puedan ir acumulando su trayectoria por la escuela y recogerla en cualquier corte temporal que se quiera, de este modo lo que se evaluaría es justamente la evolución de ese alumno, que puede haber empezado muy débilmente, que puede haber flaqueado en más de una oportunidad, pero que finalmente tiene que demostrar que es autónomo en las decisiones que corresponden a un arquitecto egresado de la Universidad de Chile.

\section{$(J C): /$}

Voy a hacer esta última intervención referida a diferentes puntos especificos. Uno es el de las comisiones y específicamente el número de miembros de las comisiones... yo cuestiono las comisiones tal como están actualmente, con una pseudorrepresentatividad de los departamentos, creo que eso no es lo más representativo de lo que es la línea docente de la escuela, pienso que las comisiones debieran ser reducidas, tal vez tres personas, de excelente nivel, la universidad tiene sistemas de calificaciones que podría ser utilizada perfectamente como referente, de esta manera también se pueden multiplicar las comisiones. Otro punto dice relación con la opción de calificar del profesor guía, otra de las tantas contradicciones que presenta el 


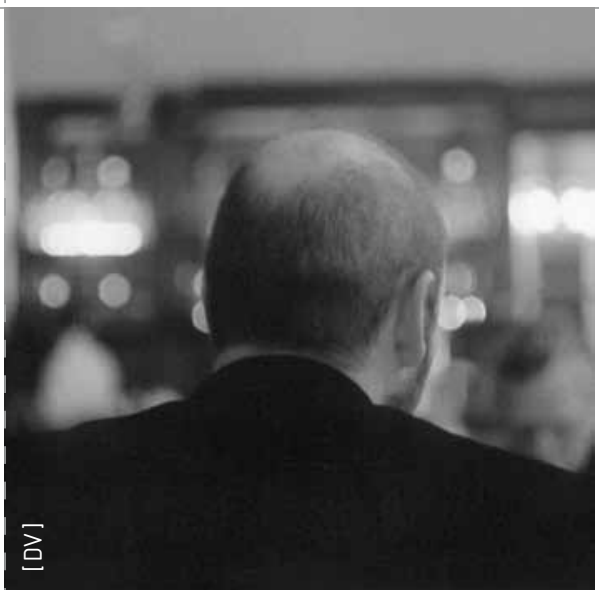

reglamento, teóricamente, los profesores de título debieran ser, aquellos profesores que tienen una experiencia y una trayectoria ta que los amerita para ser, tutores del último nivel formativo de la facultad, sin embargo a ese profesor que se le reconocen todos estos méritos, por alguna extraña razón se le desconoce la capacidad de calificar, como si indirectamente le estuvieran diciendo "usted es incapaz de ser autónomo en su calificación y de ser justo en ella; usted va a mezclar intereses de otro tipo en la calificación"..

Otro punto es el mayor plazo para las titulaciones; esto me trae a la memoria otras ocasiones en que estos plazos se han alargado y ha tenido el efecto represa: de pronto se va juntando y conforman un número tal de postulantes que se han debido arbitrar medidas extraordinarias para descomprimir la demanda de titulación como aquella época que se recuerda como la de los arquitectos "Marmicoc", creo que más que mayores plazos, es importante enlazar curricularmente el sexto año con el quinto, en este momento el corte es absoluto. Por una extraña razón la facultad comienza en abril y el proyecto de título comienza a mediados de mayo, nadie sabe por qué, pero así es. La escuela podría tener una oferta de áreas temáticas y localización de interés nacional que los alumnos pudieran inscribir ya en $5^{\circ}$ año, entonces no es efectivo que se disponga de cinco o seis meses, para un proceso que requiere antecedentes previos y si se considera que el quinto año entrega en noviembre si no me equivoco, quedan diciembre, enero, febrero, marzo, abril, mayo... son seis meses, que bien podrían servir de preparación para el proceso de titulación.

El último punto tiene que ver con las tesis, se dice "la tesis es para los que están interesados en un desarrollo más teórico, más académico de la disciplina" discrepo de ese punto de vista, se debe insistir que el proceso proyectual sea de tesis, por ejemplo en este momento hay una modificación de toda la enseñanza, con nuevas orientaciones, lo mismo ocurre en justicia, salud y desde luego en vivienda, como no va a ser posible estudiar nuevas propuestas que configuren tesis demostrativas de cómo la arquitectura responde estos nuevos requisitos. En mi opinión la tesis es consuetativa al proceso proyectual, no es un elemento paralelo o independiente de él.

\section{$(\mathrm{JL}): /$}

Respecto la idea de otras posibilidades de titulación; como la tesis o la carpeta que mencionó Jaime... Hay universidades como la de la República de Montevideo en que la gente se titula con un portafolio, que son todos los trabajos que han hecho durante la carrera. Los repasan, los revisan, los reanalizan y entregan; "esto es lo que yo soy como alumno durante todos los años". Es bastante más representativo que entregar un solo proyecto. También hay otras posibilidades de titulación que explorar, cuales son los límites de la arquitectura... del proyecto, pero del proyecto no sólo referido al diseño, sino que un proyecto de implicancia social, en el más amplio sentido de la palabra... la posibilidad de titularse con una ordenanza, con un material, con el diseño de un sistema social. Hasta que la arquitectura ya se transforme en otra disciplina; en sociología, en arte...

El último punto es reforzar esta idea del proyecto de título como la celebración máxima de la escuela, de la Universidad, el gran punto final que sea realmente un proyecto de título abierto de cara a los alumnos, con profesores que no se escuden en este anonimato a puertas cerradas para reprobar a alguien, 0 para ponerle un siete, que muchas veces, es tan discutible como una reprobación. Que lo hagan de forma abierta, que todos puedan verlo, es una escuela más universitaria, en el fondo más democrática.

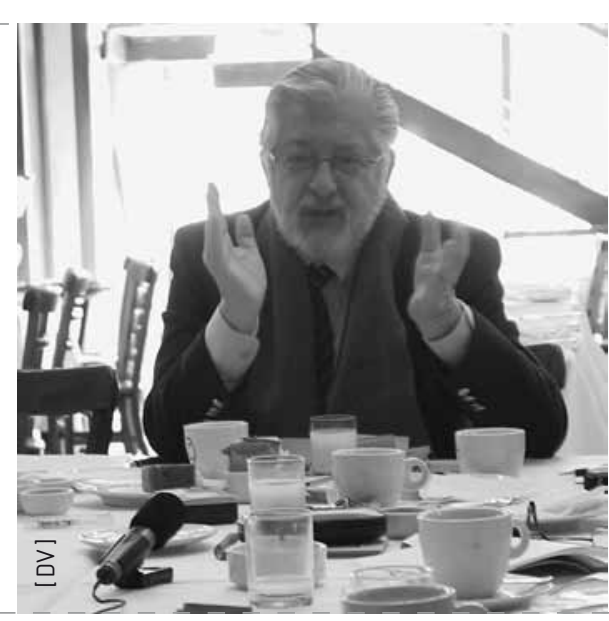

$(A G): /$

Voy a partir por lo último... recuerdo una experiencia en la Universidad de California, en Berkeley en que el examen era realizado con un sillón de cuatro asientos con ruedas, en el que se sentaba la comisión, ésta se desplazaba por el edificio, a veces tenía que cambiarse de piso, se tomaban los exámenes en amplios pasillos, asistía todo el mundo, e incluso existía el derecho a que los alumnos hicieran preguntas, después que terminaba el examen había preguntas de las personas asistentes y se abrían discusiones conceptuales importantísimas, incluso yo diría que era la mejor lección.

El título es la última vez en que e alumno estará libre para elegir el tema, el lugar, en que no tiene la presión del costo tan determinante... ahora qué es lo bueno del proyecto que yo no perdería... hemos hecho muchas críticas, pero tiene elementos positivos también... yo he visto crecer gente en el proyecto, efectivamente es un momento de maduración significativo, es un elemento positivo para corregir con los profesores de los distintos departamentos... yo siento que es muy importante, la posibilidad de participación del profesor de las especialidades en el momento del diseño... que también tenga esa posibilidad de ir viendo cómo surge el proyecto, como se desarrolla, desde la elección del lugar, las condicionantes, a la solución urbanística, hasta llegar a la solución de un problema que siempre es complicado, las instalaciones técnicas...

Ahora la otra cosa que es importante es la apertura de posibilidades, en tanto el título es un campo de experimentación y en este sentido yo creo que debemos insistir en que el alumno sienta que puede experimentar. Muchas veces hemos visto al alumno enfrentado a ciertas normativas, lo que quiero decir es que las propias condiciones que va poniendo la comisión podrían ser discutibles... 


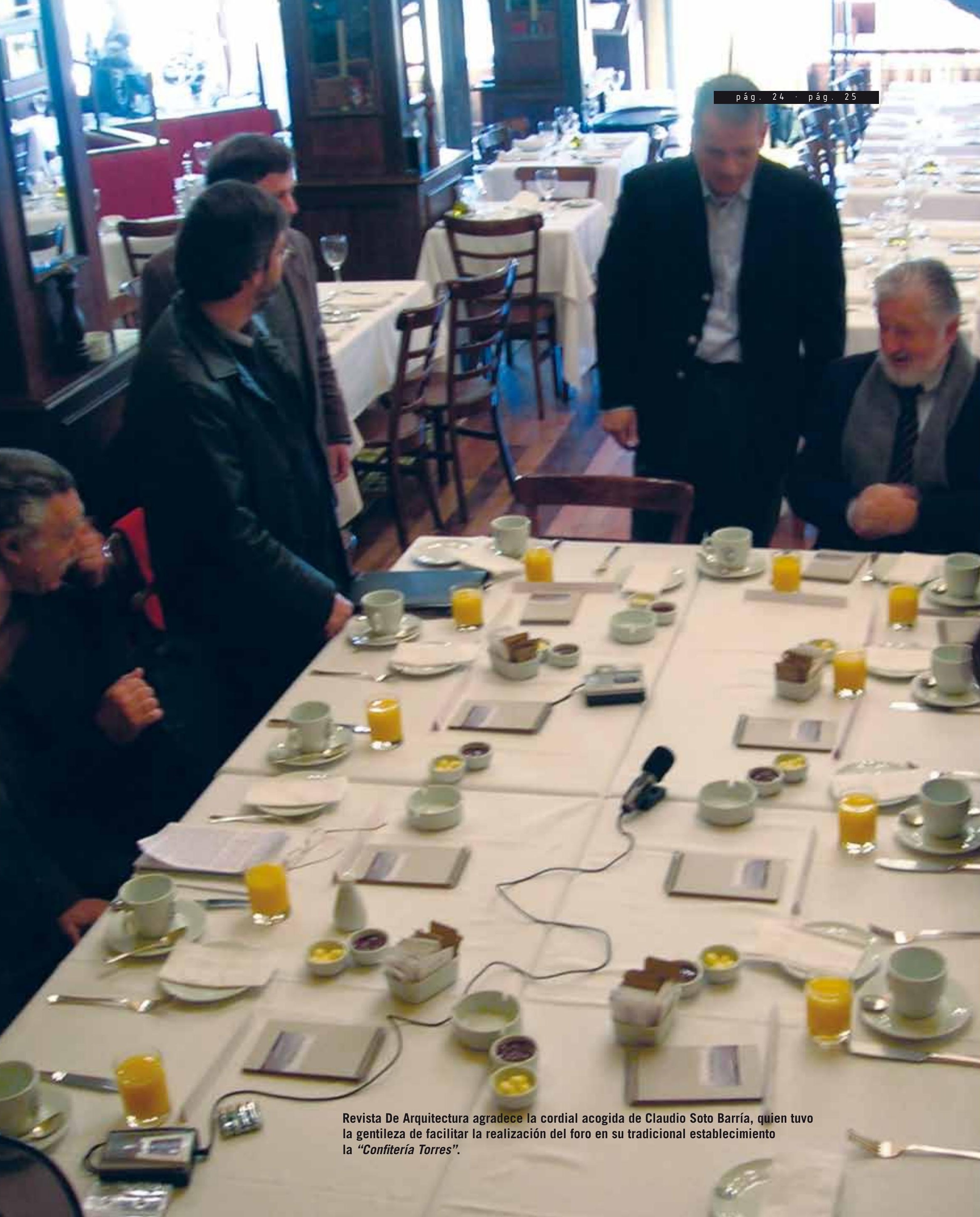




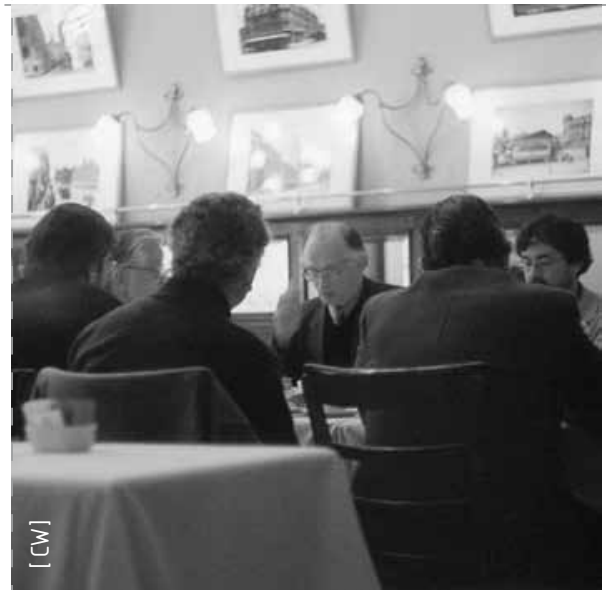

Por último, respecto el equilibrio entre la cuestión más bien conceptual y la parte de la tecnología del proyecto. Muchas veces la respuesta no es tan clara como uno desearía que fuera. Creo que una gran ganancia, a ese respecto, en los últimos años han sido los cursos de teoría de la arquitectura. Los alumnos están llegando a los otros cursos, más despiertos, el diálogo se ha enriquecido notablemente y creo que ese es un paso muy adelante que todavía no lo podemos evaluar.

\section{$(J C): /$}

Una última intervención en relación a la participación de los profesores de especialidades.

Es evidente que esa participación es importante y necesaria, pero debiera darse con mayor anticipación, y debiera continuar a lo largo de todo el proceso, porque lo que se produce ahora es que el profesor se encuentra frente a un proyecto del cual muchas veces desconoce sus orígenes, entonces va a resolver problemas y muchas veces la resolución de esos problemas, por decirlo de una manera, distorsiona lo que es la parte propositiva del proyecto; entonces es importante involucrarlo, pero con anterioridad, que conozca y sepa qué es lo que el alumno quiere hacer en su proyecto.

\section{$(\mathrm{MV}): /$}

Cuento dos o tres cuestiones porque a medida que los escucho me van viniendo a la cabeza estos trabajos que nosotros llamamos tesis...

Si yo les dijera a ustedes el trabajo del observatorio urbano de la ciudad de Santa Fe, que es uno de los trabajos más importantes que se han hecho, proviene de la tesis de un alumno, que luego fue retomada institucionalmente por un grupo de docentes de la facultad y hoy dentro de muy poquito tiempo vamos a tener el laboratorio de la ciudad

Muy pocas veces se había podido ver, o pensar, como hacer una normativa urbana para una localidad de tres mil quinientos habitantes que no es muy usual y ese es el caso de un alumno que vive en una localidad de tres mil quinientos habitantes, a cuatrocientos kilómetros de la ciudad de Santa Fe, casi como muy perdida y me pareció particularmente de interés que en su exposición pública de la tesis estuviera el intendente de esa pequeña localidad al lado de él, felicitándolo por el aporte para tres mil quinientas personas que ni siquiera tenían un dispositivo mínimo para pensar su localidad... y así podría seguir citando ejemplos de lo que a mí me parece que son actividades proyectuales tan importantes como también puedo decir que he visto uno de los mejores hospitales zonales desarrollado en ese mismo trabajo de tesis por alumnos que, como decís vos Alberto, afianzan de una manera distinta en ese último año la opción más proyectual... yo creo, les doy mi opinión de los que estamos haciendo nosotros allá: damos la posibilidad que se puedan desarrollar proyectos que puedan terminar en un trabajo normativo, que implica un alto grado de creatividad.

Por otro lado, a propósito de lo que se segundo semestre de quinto año, una materia que es teoría crítica de la arquitectura, en donde lo que se va tomando del tema de tesis, se anticipa de ese trabajo final; esta materia funciona como un buen enclave para que e alumno se vaya familiarizando en una cuestión teórica, que después va a incorporar en su proyecto final de tesis, y cuando ingresa a la tesis ya viene con esta experiencia, que le da un fuerte anclaje de antecedentes y algunas líneas de autores o cuestiones proyectuales y urbanas que se han visto ya en quinto año. Pero les confieso que creo que los trabajos más creativos, más interesantes, incluso los de mejor nivel tecnológico los he visto en esta revisaba recién de la teoría, se incorporó en el

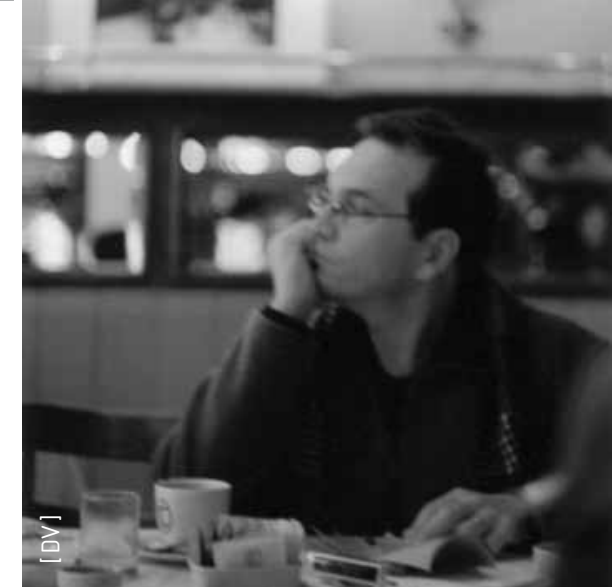

idea de un proyecto más abierto al final de la tesis, con mucha autogestión del alumno y que por esa cuestión del contacto de los alumnos que después egresan, lo que pretendemos en la facultad es que aquellos proyectos que pueden ser tomados por otros núcleos de la facultad; sea por núcleos de investigación o de algún departamento, el alumno queda durante bastante tiempo más en contacto directo con la institución llevando adelante esa propuesta proyectual. Esa es nuestra experiencia, a diferencia de hasta hace unos ocho o nueve años que solamente la tesis era un proyecto de arquitectura... mi convicción es que hay mucha arquitectura en este proyecto de tesis final, pero más diversificada, vista desde contextos más abiertos.

\section{(JD) : /}

Dame treinta segundos para plantear una cuestión que creo que no deberíamos dejar fuera y es que cualquiera sea la modalidad que se adopte para evaluar el fin de carrera, debiéramos tratar de volver a valorar más las ideas y las propuestas y no dejarnos llevar muchas veces por la súper producción de una presentación o de un examen. No sé en qué momento nuestros estudiantes descubrieron la manera de transformar una propuesta que puede ser modesta, pero valorable y la transforman a través del subcontrato de maquetistas y de modeladores de 3D en una parafernalia que muchas veces juega en contra de su propio proyecto... recuerdo que un profesor de arquitectura me decía "la buena arquitectura se reconoce en la obra gruesa" y si uno ve las entregas oficiales, por ejemplo, lo que ocurre treinta o sesenta días antes del examen, ahí está el proyecto. Nadie está en contra de una buena presentación, de un buen dibujo, de una buena maqueta, pero realmente los alumnos gastan recursos que no tienen en una presentación que es irrelevante muchas veces y le dan una cosmética al proyecto que esconde sus propios valores. 


\section{(LG) :/}

Bien... profesores, nosotros como equipo de la Revista De Arquitectura quedamos con un trabajo ya comprometido, que es transformar este foro en un documento que llegue por este medio, a la dirección académica, a la sociedad de arquitectos de la escuela, a otras escuelas, como un documento útil en beneficio de todos... yo quisiera agradecer la presencia de ustedes, la presencia de todo el equipo de trabajo de la revista: Cecilia Wolff, Constantino Mawromatis, Rubén González, Pablo Cid, Diego Vallejos y muy especialmente la gentileza de Claudio Soto que nos ha permitido realizar este foro aquí, en la Confitería Torres.

Muchas gracias a todos.

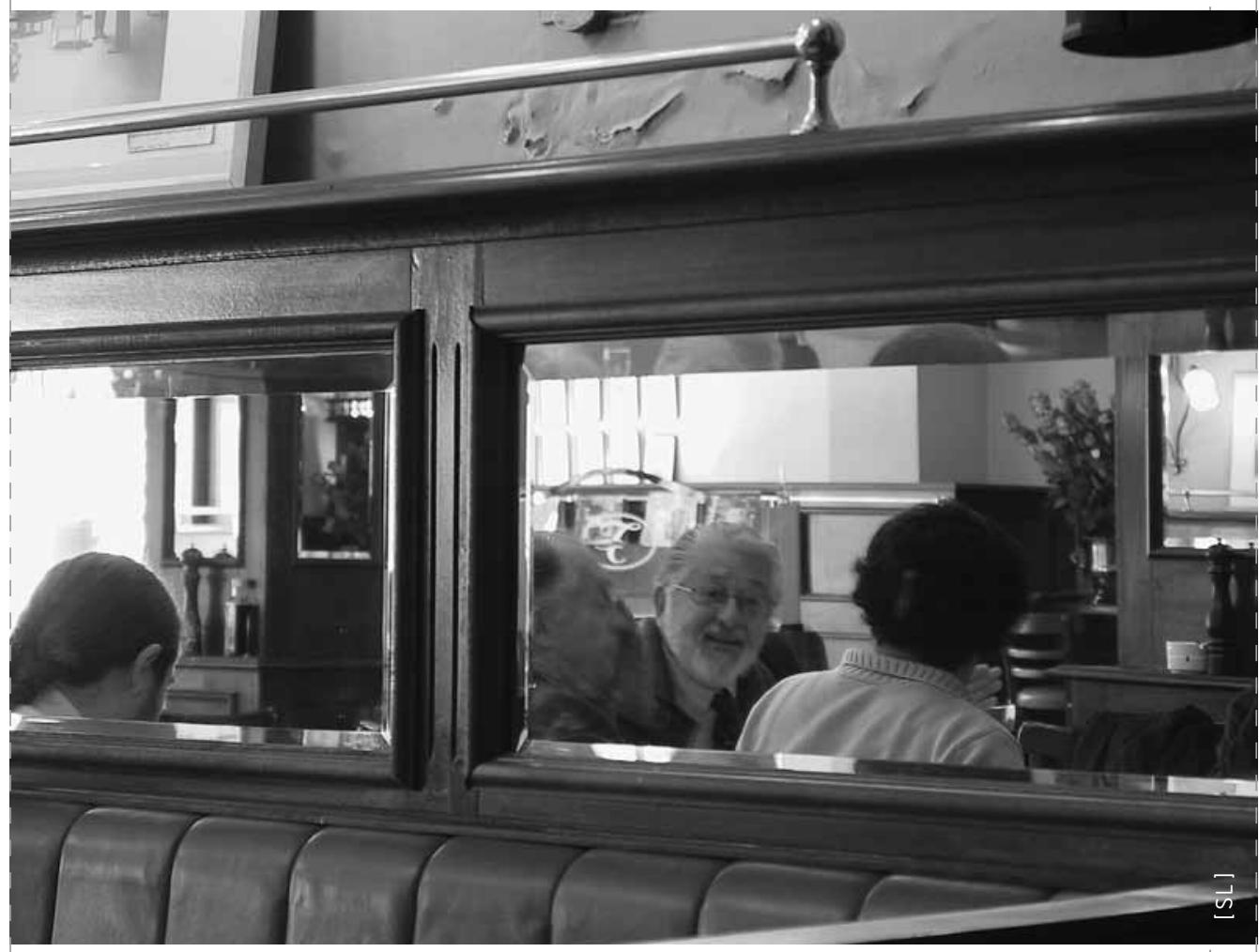

